\title{
Periosteum Derived Cells in Skeletal Tissue Regeneration
}

\author{
Johanna Bolander, Tim Herpelinck, and Frank P. Luyten
}

\section{Contents}

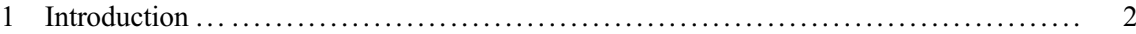

2 Primary Cells: Periosteal Cells ............................................. 4

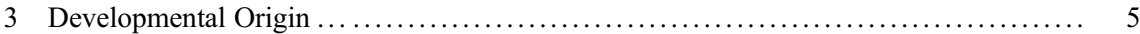

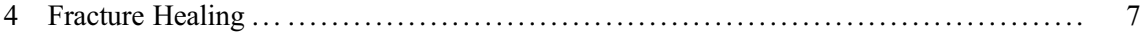

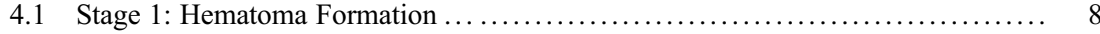

4.2 Stage 2: Reinnervation, Revascularization, and Formation of the Cartilaginous

Callus ......................................................... 9

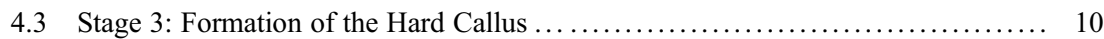

4.4 Stage 4: Cartilage Removal and Bone Formation $\ldots \ldots \ldots \ldots \ldots \ldots \ldots \ldots \ldots \ldots \ldots \ldots \ldots \ldots \ldots+10$

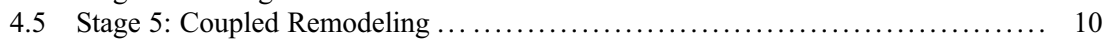

5 Identification of Skeletal Stem Cells within the Periosteum ....................... 11

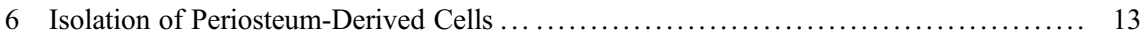

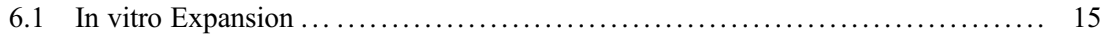

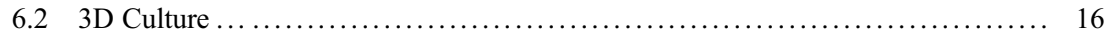

7 Periosteum Derived Cells in Regenerative Medicine ............................ 16

8 Periosteum Derived Cells for Intramembranous Fracture Healing .................. 18

9 Periosteum Derived Cells for Endochondral Fracture Healing .................... 20

10 Osteochondral Tissue Repair by Periosteum Derived Cells $\ldots \ldots \ldots \ldots \ldots \ldots \ldots \ldots \ldots \ldots \ldots \ldots \ldots \ldots$

11 Periosteal Cells in the Preclinical Setting ..................................... 24

12 Clinical Evaluation of Periosteal Cells .......................................... 28

13 The Potential of Periosteum Derived Cells as In vitro Models to Evaluate Treatments

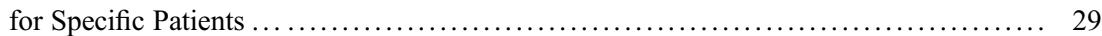

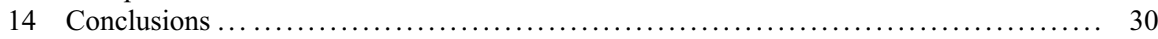

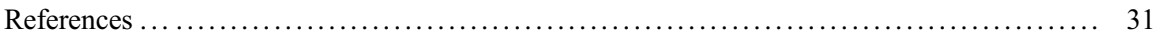

\footnotetext{
J. Bolander · T. Herpelinck · F. P. Luyten $(\bowtie)$

Tissue Engineering Laboratory, Skeletal Biology and Engineering Research Center, KU Leuven, Leuven, Belgium

Prometheus, Division of Skeletal Tissue Engineering, KU Leuven, Leuven, Belgium e-mail: johanna.bolander@kuleuven.be; tim.herpelinck@kuleuven.be; frank.luyten@uzleuven.be
}

J. M. Gimble et al. (eds.), Cell Engineering and Regeneration, Reference Series in

Biomedical Engineering, https://doi.org/10.1007/978-3-319-37076-7_6-1 


\section{Abstract}

The field of skeletal tissue engineering has in recent years been transformed by the identification of specific skeletal progenitor cell populations and their role in bone fracture healing. Specifically, progenitor cells residing within the periosteum have been shown to be crucial for bone regeneration. Importantly, this is not a phenomenon performed by one common progenitor cell, instead, distinct skeletal progenitor cell populations have been identified within the periosteum, shown to also contribute to different aspects of tissue repair. These findings represent major steps in the field of regenerative medicine, since there is currently no reliable treatment for patients with a failing endogenous repair system. Therefore, insights regarding the specific cell populations and factors that steer their homing and differentiation in vivo can aid in the development of optimized and personalized engineered treatment strategies. In this chapter, we highlight the crucial role of periosteumderived cells in bone development, homeostasis, and repair. We next provide an overview of the periosteum-residing skeletal progenitor cells identified so far and their role in bone regeneration. Subsequently, we discuss the required steps to isolate and expand periosteal cells in vitro, and the current state of the art in the use of periosteum-derived cells for bone formation and regeneration following the intramembranous, endochondral, or osteochondral tissue repair route. Finally, we present an overview of periosteal cells in the preclinical and clinical setting and discuss their future potential.

\section{Introduction}

Cell-based strategies in regenerative medicine have emerged as promising treatment alternatives when the patient's intrinsic regenerative potential is hampered (Bianco et al. 2013). Yet, the majority of developed products still faces difficulties in the translation of in vitro findings to more clinically relevant in vivo settings. It has been suggested that one of the major reasons for this is the limited attention paid to the mechanism of action in the natural healing process of the damaged tissue of interest (Bianco et al. 2013; Heathman et al. 2015). In general, the cell population(s) of choice provides the driving force of the "living" implants regenerative capacity. Thus, the success of a cell-based construct highly relies on the choice of (a) potent and reliable progenitor cell population(s) able to form the required tissue, together with the subsequent stimulatory cues to frame and support these cells. As a result, the current lack of convincing clinical success in available therapies may be an issue related to the lack of a solid scientific basis supporting a quality by design. To deal with this, the developmental engineering principle has been proposed and gained attention by fusing concepts from developmental biology with engineering principles (Ingber et al. 2006; Lenas et al. 2009a, b). The concept of developmental engineering initiated a paradigm shift in the field of regenerative medicine. Instead of developing constructs resembling the original healthy tissue, scientists have now 
started developing treatments recapitulating events in healthy tissue regeneration in order to overcome the existing limitations present in a compromised environment.

A crucial aspect when designing a cell-based regenerative construct is defined as having sufficient knowledge with regards to the anatomical and physiological properties of the original tissue to be restored or replaced. Thereafter, critical factors required for the regeneration should be combined to develop a functional, engineered solution for a well-defined clinical problem. With this in mind, the chosen factors (i.e., cells, stimulatory factors, 3D matrix) used in the development of a cell-based construct should therefore be inspired by the essential or even crucial factors required and sufficient for a natural healing process.

Bones represent unique organs in the human body due to their capability to regenerate upon damage without scar tissue formation. However, when the fracture environment is compromised, for instance, due to the large size, the patient has an impediment of the natural repair system (disease, genetic disposition, poor life style) or the surrounding environment including vascularity is severely affected, additional repair strategies are required for successful healing. Examples include massive trauma, but can also arise secondary, such as after osteosarcoma resection surgery or in patients with co-morbidities such as diabetes, and may lead to the development of a nonunion. Unsuccessful treatment of a nonunion leads to significant loss of mobility and independence with substantial loss in quality of life. In addition, prolonged hospitalization and work incapacity primes towards a large economic burden for the patient as well as society. Unfortunately, prolonged failure to regenerate the defect may even lead to amputation of the limb.

In recent years it has been established that the periosteum is not only largely involved in bone strength maintenance, and its preservation is crucial for normal bone repair (Duchamp de Lageneste et al. 2018). Consequently, periosteal cells have gained an increasing interest from an engineering perspective for skeletal tissue engineering purposes. The inner cambium layer of periosteum contains a heterogeneous cell population including fibroblasts, endothelial, and progenitor cells. The population of progenitor cells can be further separated based on their fate commitment. Even though it can be hypothesized that the detailed identification of the specific populations of skeletal progenitor cells present in the periosteum has just started, several specific progenitor cell populations have recently been identified that contribute to intramembranous bone formation and endochondral fracture healing and are listed in Table 1. Upon isolation of periosteum derived cells (PDCs), the heterogeneous and plastic-adherent populations are expanded and exhibit great clonogenicity, growth, and differentiation capacity. Even though their bone formation potential has been confirmed to exceed those of the more commonly used progenitor cells such as bone marrow stromal cells or adipose tissue derived progenitor cells (Agata et al. 2007; Colnot 2009; Hayashi et al. 2008; Yoshimura et al. 2007), only a fraction of research publications in the field of skeletal tissue regeneration report the use of PDCs. This is most likely due to limited access.

The periosteum is easily accessible once a fracture occurs, but the periosteum's critical role in fracture healing limits the maximum size of the biopsy, in order not to jeopardize the healing. Therefore, the use of human periosteum derived cells for 
Table 1 Overview of skeletal stem cells identified so far

\begin{tabular}{|c|c|c|}
\hline \multicolumn{3}{|c|}{ Skeletal stem cells identified in mouse } \\
\hline Candidate markers & $\begin{array}{l}\text { Location of } \\
\text { discovery }\end{array}$ & Reference \\
\hline $\begin{array}{l}\mathrm{CD} 45^{-} \text {Ter119- } \\
\text { PDGFR } \alpha^{+}\end{array}$ & $\begin{array}{l}\text { Perivascular } \\
\text { cells }\end{array}$ & (Morikawa et al. 2009) \\
\hline CD146 & $\begin{array}{l}\text { Perivascular } \\
\text { cells }\end{array}$ & (Sacchetti et al. 2007) \\
\hline Nestin (overlapping with LepR) & $\begin{array}{l}\text { Perivascular } \\
\text { cells }\end{array}$ & $\begin{array}{l}\text { (Isern et al. 2014; Kunisaki et al. 2013; } \\
\text { Mendez-Ferrer et al. 2010; Ono et al. } \\
\text { 2014) }\end{array}$ \\
\hline Grem1 & $\begin{array}{l}\text { Growth plate } \\
\text { and } \\
\text { metaphysis }\end{array}$ & (Worthley et al. 2015) \\
\hline $\begin{array}{l}\mathrm{CD}^{2} 5^{-} \text {Ter119 } \\
\text { thy }{ }^{-} 6 \mathrm{Tie}^{-}{ }^{-} \mathrm{CD}^{-} \mathrm{CDh}^{-} 105^{-} \mathrm{CD} 200^{+}\end{array}$ & Growth plate & (Chan et al. 2015) \\
\hline PTHrP & Growth plate & (Mizuhashi et al. 2018) \\
\hline CD73 & Growth plate & (Newton et al. 2019) \\
\hline Gli1 & Growth plate & (Shi et al. 2017) \\
\hline Thy $^{-}{ }^{-} 6 \mathrm{C} 3^{-}$CD200+, CD105- & Periosteum & (Debnath et al. 2018) \\
\hline Postn & Periosteum & (Duchamp de Lageneste et al. 2018) \\
\hline HoxA11 & Periosteum & (Pineault et al. 2019) \\
\hline $\mathrm{Mx}^{+} \alpha-\mathrm{SMA}^{+}$ & Periosteum & (Ortinau et al. 2019) \\
\hline \multicolumn{3}{|c|}{ Skeletal stem cells identified in man } \\
\hline $\begin{array}{l}\mathrm{CD} 146^{-} \mathrm{PDPN}^{+} \mathrm{CD}^{+} 3^{+} \\
\mathrm{CD}_{164^{+}}\end{array}$ & Growth plate & (Chan et al. 2018) \\
\hline
\end{tabular}

research purposes is limited to settings where an orthopedic surgeon or traumatologist is committed and able to collect a limited sample. Post-mortem collection can be an alternative, but requires the ability to collect the sample within 6 hours and requires additional administrative procedures and ethical approval in most countries. Upon successful collection and in vitro expansion of periosteum derived cells, several interesting and innovative routes have been undertaken in vitro and in vivo to utilize and understand the unique ability of PDCs to improve or restore the regenerative potential of bone defects.

\section{$2 \quad$ Primary Cells: Periosteal Cells}

The bony skeleton has a remarkable regenerative potential, generated by pools of skeletal stem and progenitor cells which differentiate into bone and cartilage to consolidate fractures. An essential source of these cells is the periosteum, the tissue which envelops nearly every bone. The periosteum is involved in bone growth, remodeling, and repair. In this chapter, we summarize the current knowledge on bone regeneration, the role of the skeletal stem and progenitor cells in this process, and the periosteum as a source thereof and their application in tissue engineering. 


\section{Developmental Origin}

Bone is formed through two different processes. One involves the direct formation of bone within a membrane. This is referred to as primary, direct, or intramembranous ossification, which forms the flat bones of the skull, parts of the mandible and the lateral ends of the clavicles. The remainder of the axial and appendicular skeleton including the long bones is formed by secondary or endochondral ossification, a process involving the formation of a temporary cartilage template, which is subsequently replaced by bone.

During long bone development, undifferentiated mesenchymal cells condense into the shape of the bone. The mesenchymal condensations then undergo differentiation and become embedded in a cartilaginous matrix. At this point in time, the outline of the bone is in place but the future joint areas, the joint interzones, are still filled with cells. As the ephiphyseal end of the bone acquires its shape, the cells in the interzones undergo apoptosis, thereby forming the joint cavity and completing the blueprint of the prospective bone and joint. The cartilage anlage of the bone then undergoes radial and longitudinal expansion by interstitial and appositional growth, respectively. The cartilage template itself is enveloped by a cellular condensation of perichondrial cells. The expansion of the condensate is driven by proliferating chondrocytes, which give rise to columnar structures. Towards the end of the columns, the chondrocytes gradually undergo hypertrophy. Hypertrophic chondrocytes then enter apoptosis to leave lacunae in the matrix or transdifferentiate into osteoblasts. These lacunae are subsequently invaded by blood vessels, which provide essential nutrients, oxygen, and mesenchymal cells that differentiate into osteoblasts. The osteoblasts remodel the cartilaginous matrix and synthesize the first bone matrix, thereby forming the primary center of ossification. The bone lengthens as the proliferating chondrocytes progressively undergo hypertrophy, thereby moving up the ossification front. The perichondrium adjacent to the primary ossification center now forms the periosteum of the new long bone (Moreira et al. 2000) (Fig. 1a).

The periosteum itself is a double-layered tissue which envelops nearly every bone in the body (Dwek 2010) (Fig. 1b). It is connected to the bone by the fibers of Sharpey. The inner layer is highly osteogenic, while the outer fibrous layer is collagenous and poor in elastin fibers. Throughout the surface of the fibrous layer runs an extensive vascular and neural network, which in part runs through the bone cortex. The vasculature of the outer layer is one of the major blood supplies of the bone. Upon close examination of the outer periosteal layer, it can be further dissected into two substrata: the aforementioned highly innervated and vascularized layer and a deeper more fibroelastic region. This layer is located directly adjacent to the inner periosteal layer, contains more elastic fibers than the superficial layer, and is not very vascularized. The periosteal tendons are attached to this stratum.

The inner layer of the periosteum is densely populated with fibroblasts, progenitor cells, and osteoblasts (Allen et al. 2004). These osteoblasts directly line the cortex of the bone. Referencing the cambium layer of the trees, which is responsible for appositional growth and creates the characteristic ring pattern, the inner layer of 


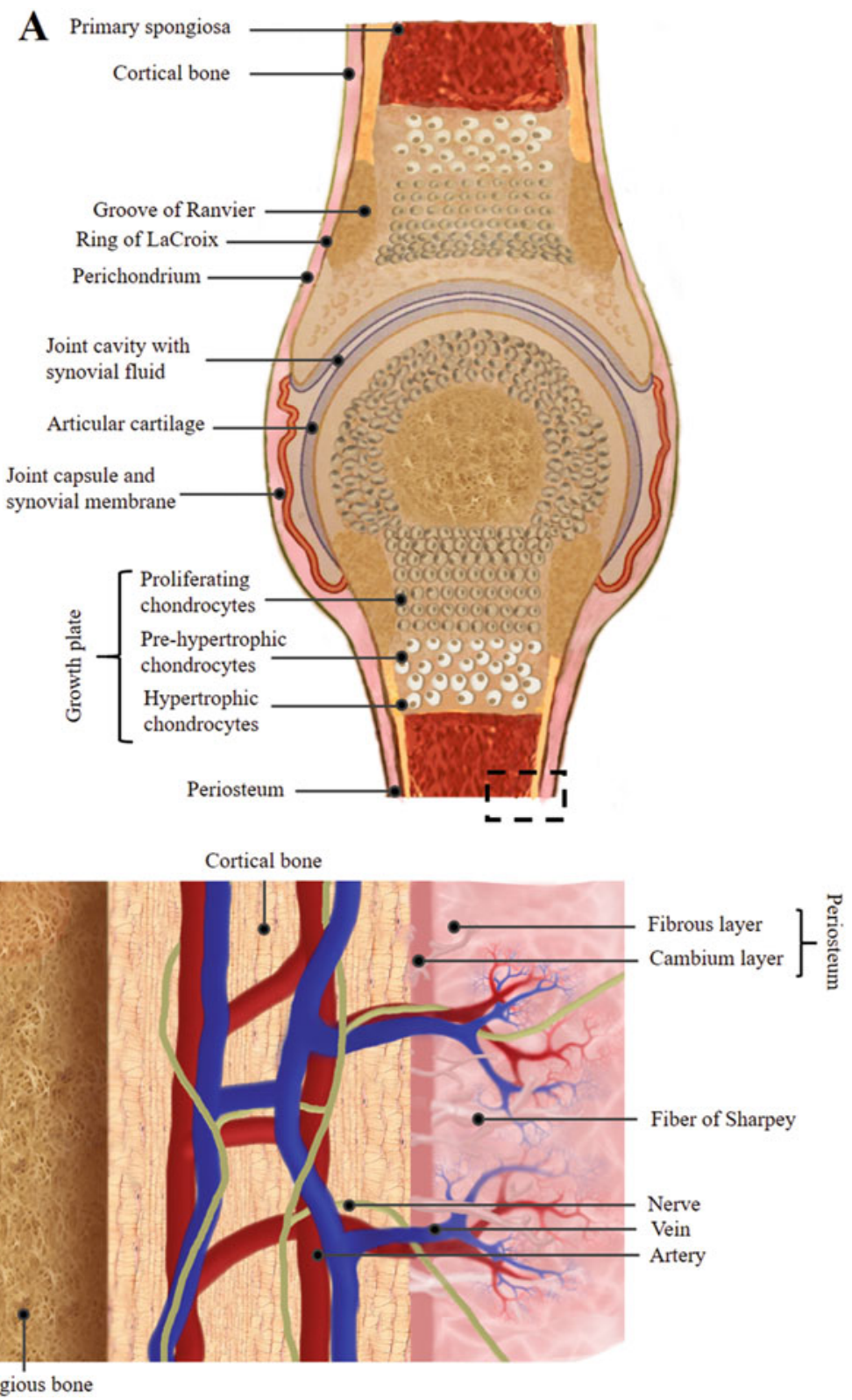

Fig. 1 Anatomy of joints and the periosteum. Schematic drawing of a synovial joint (a) An enlarged view of the boxed area is shown in (b) For clarity, the fibrous layer of the periosteum is folded backwards 
the periosteum was named the cambial layer by Henri-Louis Duhamel in 1742. In a strikingly parallel fashion, the cambial layer of the periosteum is responsible for the radial growth of bones. The cambial layer also hosts a vascular and neural network. Resulting from the large presence of vessels, a significant number of pericytes can be found in this stratum of the periosteum (Diaz-Flores et al. 1992).

While the growth plate chondrocytes continue to lengthen the bone, the periosteal osteoblasts lining the cortex begin to deposit bony matrix to expand the radius of the bone by intramembranous ossification. Meanwhile, joint cavitation finishes at the interzones, leaving the articular surfaces uncovered. This allows the formation of articular cartilage (Archer et al. 2003). At the periphery of the cartilage anlage, the fibrous capsule of the joint is formed in a similar fashion as the perichondrium and periosteum condensed. Consequently, the fibrous joint capsule, the perichondrium, and the periosteum share similar developmental pathways in their formation.

The periosteum surrounds the diaphysis up to the groove of Ranvier, a circumferential groove in the periphery of the epiphyseal cartilage, where it provides both osteoblasts and chondrocytes for appositional growth. It thereby also encapsulates the perichondrium lining the epiphyseal growth plate, the ring of LaCroix, to provide additional structural integrity. Beyond the groove of Ranvier, the periosteum transitions into the perichondrium which is in turn continuous with the joint capsule (Davies 1963).

In later stages of development, blood vessels also invade the epiphyseal cartilage and a secondary ossification center is formed. As secondary centers of ossification are mostly intra-articular, they are not covered in periosteum, contrary to the primary centers of ossification.

Both the periosteum and the growth plates continue to increase the size of the bones until skeletal maturity is reached. At this point the growth plates undergo ossification, otherwise referred to as closure of the growth plates. The periosteum becomes relatively quiescent and takes on the role of a reservoir of osteoblasts and osteochondroprogenitors. Throughout life, these cells delicately interplay with bone resorbing osteoclasts to continuously remodel the bone cortex in response to mechanical loading.

\section{$4 \quad$ Fracture Healing}

The relative quiescence of the skeletal progenitor cells within the periosteum is abruptly terminated upon fracture of the bone. The degree of periosteal cell activation depends on the location of the fracture and its mechanical stability. If the fracture occurs in the metaphysis of the bone, the relative contribution of the periosteum to the healing process is rather limited, as the spongious bone of the metaphysis is rich in osteogenic bone marrow stromal cells. Diaphyseal fractures however are, if not properly fixated, bridged by a healing response concerted primarily by the periosteum. Conversely, rigid fixation hampers the periosteal response (McKibbin 1978). Bone fracture healing involves most often both intramembranous and endochondral ossification and is generally described as a five-stage process. 


\subsection{Stage 1: Hematoma Formation}

The hematoma is the crucial initial signaling center which initiates the cellular and molecular cascades of fracture healing, and its removal leads to defective bone healing (Mizuno et al. 1990). The hematoma is formed as a result of the rupture of blood vessels at the moment of trauma (Fig. 2a). At this point, the extrinsic coagulation cascade activates in response to the exposed subendothelial tissue factor (TF) (Broos et al. 2011). This leads to the activation of thrombin, which converts inactive fibrinogen into fibrin, which forms a cross-linked fibrin clot. Concomitantly, platelets activate and translocate their integrin receptors to the membrane. These have high affinity for fibrin, fibrinogen, von Willebrand Factor (vWF), thrombospondin, and fibronectin, leading to platelet aggregation. The platelets become trapped in the fibrin clot and degranulate. Inside platelet granules is a large store of mediators of inflammation such as cytokines, chemokines, and growth factors. Therefore, the stage of hematoma formation is accompanied by a phase of inflammation.

\subsubsection{The Clearing of Debris}

The release of the pro-inflammatory cytokines interleukin-1 (IL-1), interleukin-6 (IL-6), and tumor necrosis factor alpha (TNF $\alpha$ ) recruits neutrophils, lymphocytes, and monocytes to the fracture site by promoting their extravasation. Neutrophils are the first to arrive to the defect site (Xian et al. 2004) and start clearing debris and dead cells by phagocytosis (Stuart and Hehir 1992). Additionally, neutrophils play an important role in preventing sepsis (Segal 2005).

At the same time, the damaged edges of the bone need to be eroded, meaning high numbers of osteoclasts are required. This is also mediated by the immune system, as

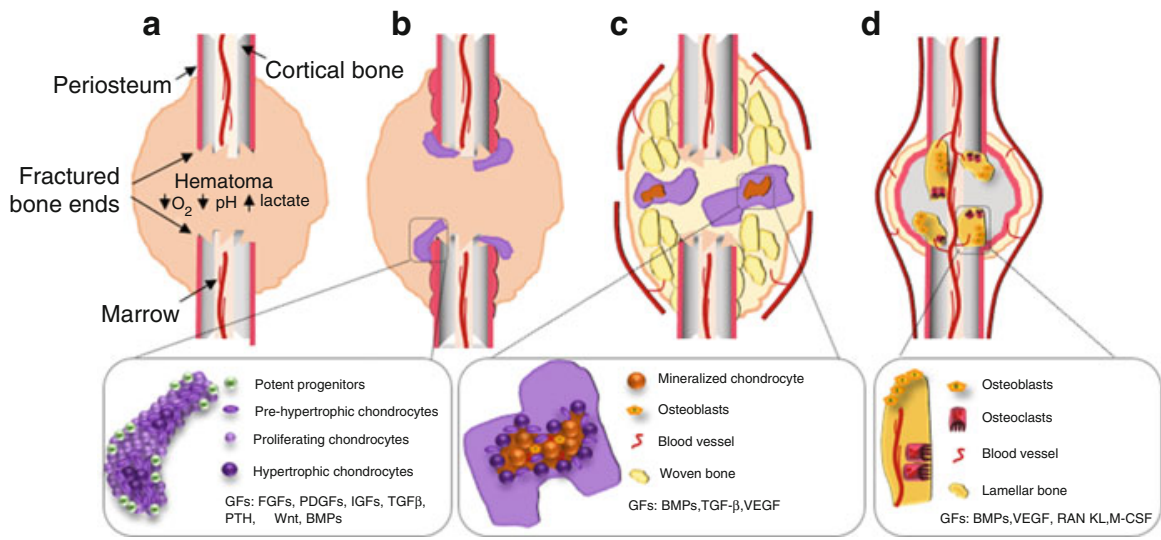

Fig. 2 The fracture healing cascade. Immediately after fracture a hematoma is formed which initiates fracture healing (a). Stem and progenitor cells in the periosteum undergo rapid expansion and begin to form a soft cartilaginous callus (b). The vascularized callus becomes weight-bearing as the hard callus is formed. (c) Cartilage is then removed and replaced by bone, later followed by the coupled remodeling of the newly formed bone (d) 
receptor activator of nuclear factor kappa-B ligand (RANKL) produced by activated T-lymphocytes and NK cells can induce the differentiation of osteoclasts from monocytes and B-lymphocytes (Kong et al. 1999; Manabe et al. 2001).

\subsubsection{Recruitment of Stem and Progenitor Cells}

The inflammatory ligands released by the platelets and type 2 macrophages in the hematoma, specifically TNF $\alpha$ and stromal cell-derived factor 1 (SDF-1, CXCL12), recruit stromal and periosteal stem/progenitor cells to the site of tissue injury (Bocker et al. 2008; Kitaori et al. 2009). This recruitment is maintained by signals from the invading immune cells. The macrophage-derived chemokines MCP-1 and CXCL7, produced by NK cells, have both been found to be involved in recruiting progenitors from the periosteum, endosteum, and bone marrow (Almeida et al. 2016; Ishikawa et al. 2014) As a result, the initial migratory signals released by the degranulating activated platelets are sustained, albeit through different molecules, by the innate immune system. Concomitantly, interferon-gamma (IFN- $\gamma$ ) and TNF $\alpha$ released by NK cells and T-lymphocytes (Croitoru-Lamoury et al. 2011; Dorronsoro et al. 2014) activate the immunosuppressive functions of the stem and progenitor cells. The bestowal of immunosuppressive properties onto a cell type by cells of the immune system is referred to as licensing, which is used to control the inflammatory phase.

\subsection{Stage 2: Reinnervation, Revascularization, and Formation of the Cartilaginous Callus}

The growth factors initially released by platelets and later by macrophages in the hematoma induce activation and rapid proliferation of periosteal progenitors. In particular, the platelet-derived growth factor (PDGF) and fibroblast growth factor (FGF) pathways initiate a rapid cell expansion in the cambial layer, resulting in thickening of the periosteum. Periosteal cells distal from the fracture differentiate into osteoblasts and drive intramembranous ossification to increase stability at the broken ends. Cambial cells proximal to the fracture invade the hematoma, where the fibrin clot acts as a temporary scaffold, and start producing cartilaginous matrix. The hematoma is then rapidly replaced by hyaline cartilage, formed primarily by PDCs. This cartilaginous structure represents the soft callus, a transient tissue which acts as a template for the further regeneration of the bone. It bridges the gap created by the fracture (Fig. 2b) and provides some stabilization of the fracture.

Concurrent with the formation of the callus, blood supply is restored through revascularization. This process is regulated by the angiopoietin and vascular endothelial growth factor (VEGF) pathways. The angiopoietins are vascular morphogenetic proteins, which promote the ingrowth of new vessels from preexisting vessels in the periosteum (Lehmann et al. 2005). Neo-angiogenesis on the other hand is mainly regulated by the VEGF pathway and progresses differently depending on the fracture. In the absence of displacement, vessel sprouting mainly occurs from within the medullary arterial system. However, if major displacement occurs, the 
periosteum is the main source of new vessels, only followed by the medullary cavity later on (Rhinelander and Baragry 1962).

Reinnervation of the fracture site slightly precedes revascularization and is orchestrated by periosteal cells and macrophages. In response to nerve growth factor (NGF), periosteal nerve fibers begin to sprout dendrites and undergo duplication before invading the fracture callus ( $\mathrm{Li}$ et al. 2019). Blood vessels and nerve fibers follow very similar paths in the skeleton (Bjurholm et al. 1988), but nerves are thought to provide the template of the branching pattern by attracting new vessels via VEGF signaling (Li et al. 2013).

\subsection{Stage 3: Formation of the Hard Callus}

Next, subperiosteal intramembranous ossification creates a bony hard callus, making the fracture callus mechanically stable and weight-bearing (Fig. 2c). At this time, the callus consists of two components: the hard and soft callus, where respectively intramembranous and endochondral ossification take place (Einhorn 1998; Schell et al. 2017).

\subsection{Stage 4: Cartilage Removal and Bone Formation}

Calcification of the soft callus follows a similar mechanism as endochondral ossification at the growth plate. Proliferating chondrocytes exit from mitosis, undergo hypertrophy, and produce pro-angiogenic ligands such as VEGF. The invading vessels bring with them perivascular cells that are osteoblast progenitors (Maes et al. 2010). This process leads to the transition of the callus into calcified cartilage, a structure which is nearly identical to the primary spongiosa found at the growth plate.

\subsection{Stage 5: Coupled Remodeling}

The callus is now fully composed of woven bone and surrounded by a new cortex. At this stage the bone enters the phase of coupled remodeling: osteoblasts deposit bone matrix to create a fully mechanically competent lamellar structure, while osteoclasts resorb excessive matrix from the transitional callus to restore the medullary cavity (Fig. 2d).

It is clear that endochondral fracture healing has strong parallels to the endochondral bone forming pathway during development. Both progress through a cartilage intermediate, in which chondrocytes proliferate, swell, and die, to ultimately be replaced by bone. However, where in development the role of the periosteum is restricted to appositional growth by intramembranous ossification, its role becomes much more varied in endochondral fracture healing. It is the source of the osteochondral progenitors which form the cartilaginous soft callus and the 
osteogenic progenitors which largely form the hard callus. While the progenitor cells located in the bone marrow, BMSCs, actively contribute to the healing, their role is secondary to the PDCs. Because the PDCs are so crucial in fracture healing and are able to recapitulate bone formation as seen during development, they can be considered a prime cell source for skeletal tissue engineering and developmental engineering in particular (Lenas et al. 2009a, b).

\section{Identification of Skeletal Stem Cells within the Periosteum}

The ideal cell for a developmentally engineered implant for fracture repair is a skeletal stem cell (SSC), preferably of periosteal origin due to their critical role in fracture healing (Duchamp de Lageneste et al. 2018). By definition of a stem cell, this would mean a cell that is able to self-renew and differentiate into multiple cell fates, thereby contributing to tissue ontogeny, homeostasis and regeneration (Bianco and Robey 2015). In recent years, multiple postnatal, lineage-restricted SSCs have been identified in multiple compartments of the bone in both human and mouse.

Groundbreaking work in identifying the first bone marrow-derived cells capable of restoring cartilage, bone, stromal tissues, and the hematopoietic compartment was performed in the 1960s by Tavassoli and Crosby (Tavassoli and Crosby 1968). Twenty years later, the concept of multipotent cells, capable of in vivo self-renewal, was proposed (Owen and Friedenstein 1988), shortly thereafter dubbed mesenchymal stem cells (MSCs) (Caplan 1991). These cells were characterized as plasticadherent, immunosuppressive, capable of in vitro colony formation, in vitro differentiation into the osteogenic, chondrogenic, and adipogenic lineage and in vivo selfrenewal. They express the cell surface proteins CD73, CD90, and CD105, but no hematopoietic lineage markers.

Unfortunately, nonskeletal fibroblastic cells have also been labeled multipotent mesenchymal stem cells by their ability to make in vitro bone, cartilage, and fat (Via et al. 2012). The term MSC should be therefore be avoided for clarity issues. Moreover, it is fundamentally flawed, as no adult stem cell should be called a "mesenchymal" cell, since this term is reserved for an embryonic tissue. In current literature, MSCs have thus become a heterogeneous aggregate of plastic-adherent cells capable of tri-lineage differentiation in vitro, leading to great inconsistencies and the impediment of clinical applications based on stromal stem cell populations (Robey 2017). In light of the recent identification of bona fide SSCs within the skeleton, it has been proposed to completely abolish the term MSC and adopt the term bone marrow stromal cell (BMSC) to refer to the original "MSC" (Bianco and Robey 2015).

Skeletal stem cells have been described in the growth plate, in association with blood vessels as pericytes, the bone marrow, the periosteum, and fracture calluses. A multipotent perivascular population with in vivo self-renewal was described by Morikawa et al. as $\mathrm{CD}^{-} 5^{-} \mathrm{Ter} 119^{-} \mathrm{Sca}^{+}{ }^{+} \mathrm{PDGFR} \alpha^{+}$cells, with in vitro osteogenic, chondrogenic, adipogenic clonogenicity (Morikawa et al. 2009). Other pericyte-like SSCs are found in the bone marrow and express the surface marker CD146 
(Sacchetti et al. 2007). These cells are of subendothelial origin, are clonogenic, and give rise to a bone ossicle in vivo which supports hematopoiesis.

Multiple SSCs have been described in the murine bone marrow, although caution when interpreting these data is advised due to the absence of highly specific markers (Mendez-Ferrer et al. 2015). Nestin is commonly used to refer to bone marrow stromal stem cells. Indeed, in the bone marrow resides a self-renewing perivascular cell positive for Nestin, capable of osteochondral differentiation (Mendez-Ferrer et al. 2010). Later studies demonstrated a partial overlap between a subpopulation of Nestin-positive cells and cells expressing leptin receptor (LepR) throughout the bone marrow (Kunisaki et al. 2013). While LepR ${ }^{+}$cells are indeed a major source of osteogenic and chondrogenic cells throughout adulthood (Zhou et al. 2014) and share an overlap with Nestin-positive cells, this can in part be attributed to the limitations related to the Nestin-GFP label. Moreover, over 17 different stromal subpopulations express LepR (Baryawno et al. 2019), less than $10 \%$ of which is capable of colony formation (Zhou et al. 2014). These labels are therefore not markers for bona fide SSCs (Zhou et al. 2014).

Gremlin-Cre traced cells (Worthley et al. 2015) located in the murine metaphysis have demonstrated all hallmarks of a true SSC. Furthermore, neither Nestin-Cre nor LepR-Cre are capable of tracing these Grem $1^{+}$cells. This would indicate that these cells are true SSCs, found at the boundary of the growth plate. The growth plate itself is indeed a reservoir of stem cells, where at least two more stem cell populations are driving the clonal expansion that keeps bones growing (Mizuhashi et al. 2018) (Newton et al. 2019). A fourth stem cell population at the growth plate is marked by Glioma-associated oncogene 1 (Gli1) and appears crucial for the maintenance of bone mass in postnatal life (Shi et al. 2017).

Chan et al. defined a human SSC population which is hematopoietic lineage negative, does not express the pericyte marker CD146, but is positive for CD164, podoplanin (PDPN), and CD73 (Chan et al. 2018). The nonoverlap can be explained by the ability of the pericyte-like cell to give rise to fat and its subendothelial localization. In addition, a bone, cartilage, and stroma precursor derived from Chans SSCs is CD146 ${ }^{+}$. In previous work, Chan et al. had identified a mouse SSC, which is $\mathrm{CD}^{-} 5^{-}$Ter1 $19^{-} \mathrm{Tie}^{-} \mathrm{AlphaV}^{+} \mathrm{Thy}^{-}{ }^{-} \mathrm{C}^{-}{ }^{-} \mathrm{CD} 105^{-} \mathrm{CD} 200^{+}$(Chan et al. 2015). While the cell surface markers do not appear to correlate well between mouse and human, the identification was performed based on transcriptome similarity, measured through single-cell RNA sequencing. Both SSCs were discovered in the growth plate, but the hSSC could also be isolated from the periosteum, the adult femoral head, and the fracture callus. In addition, hSSC-like cells can be generated from iPSCs or BMP2treated human adipose stroma (HAS).

While of great importance for our knowledge of bone in growth and homeostasis, periosteal stem cells are of particular interest as a cell source for clinical application in a tissue engineering context. It is widely accepted that the SSC responding to fracture is located in the periosteum (Marecic et al. 2015). Colnot and colleagues described a multipotent periosteal stem cell (PSC) dependent on the presence of the matrix protein Periostin (Duchamp de Lageneste et al. 2018) which gives rise to most cells in the fracture callus. Another periosteal stem cell upstream of the LepR-Cre and 
Osx-Cre stromal cell populations is marked by expression of HoxA11 (Pineault et al. 2019). A third PSC is marked by expression of Mxl and $\alpha$-smooth muscle actin $(\alpha-$ SMA). These cells and their progeny gave rise to most of the fracture callus and were also found to express CD140 and Grem1, but not Nestin (Ortinau et al. 2019).

A final periosteum-specific SSC and two distinct periosteal progenitor populations were identified by Debnath et al., using a green fluorescent protein (GFP) cathepsin K reporter mouse (Debnath et al. 2018). All populations were negative for hematopoietic lineage markers, did not express CD90.2 and 6C3, and had low expression of CD49f and CD51. The periosteal stem cell (PSC) was defined $\mathrm{CD} 105^{-} \mathrm{CD} 200^{+}$, while the progenitor populations were $\mathrm{CD} 105^{-} \mathrm{CD} 200^{-}$and $\mathrm{CD} 105^{+} \mathrm{CD} 200^{\text {var }}$. A human equivalent of the PSC was also identified by the $\mathrm{CD} 105^{-} \mathrm{CD} 200^{+}$signature. These stem and progenitor cells were found to exclusively perform intramembranous ossification during homeostasis, but acquired osteochondrogenic differentiation potential during fracture healing. This plasticity is well in line with the role of the periosteum in development and repair.

Taken together, a plethora of SSCs has been described across all skeletal compartments including the periosteum, summarized in Table 1 and recently reviewed (Ambrosi et al. 2019). The extent to which these cells are truly distinct subpopulations and not a common population described by different markers in various settings and models remains to be addressed. Another issue is the limited work performed in man. However, in the context of fracture healing, it can be concluded that the periosteum appears a very relevant source of stem and progenitor cells.

\section{Isolation of Periosteum-Derived Cells}

Human periosteum-derived cells (hPDCs) can be isolated from patients undergoing surgery for bone fracture repair without the need of additional surgery. Of note, the periosteum becomes gradually thinner with age and is nearly invisible in patients of high age, reducing both the number of cells to isolate, but also the osteochondrogenic potential (Moore et al. 2014). The quality of the samples and the number of cells possible to isolate is therefore highly dependent on the age of the patient, with minors or adolescents being the ideal donors. Generally, periosteal biopsies are small $\left(\sim 0.5 \mathrm{~cm}^{2}\right)$ as to not jeopardize a positive clinical outcome and approximately 4000 plastic adherent cells can be isolated/mg of periosteal tissue after the first passaging (Fig. 3a). Since most layers of the periosteum are generally cell-poor, it is highly advised to optimize the cell isolation procedure for the specific setting. Primary culture of hPDCs therefore usually starts out in a 6-well plate, as hPDCs tend to slow down their proliferation speed at low confluency. Mouse periosteumderived cells (mPDCs) are slightly easier to obtain, since after sacrifice of the mice, periosteum from entire long bones (e.g., femur, tibia, fibula) can be stripped to collect cells. The processing of periosteum from tissue to single cell is species agnostic and described below.

A combination of mechanical and enzymatic dissociation of the tissue is optimal for maximum cell yields. The mechanical step usually involves the cutting of the 
periosteum into the smallest possible pieces $(\sim 0.5 \mathrm{~mm})$ with a scalpel or razor blade, which optimizes the surface area exposed to the proteolytic enzymes. The periosteum is significantly easier to cut after removal of excessive liquid by gently placing on a sterile gauze pad.

Regarding enzymatic digestion, multiple options are available. Liberase has been used (He et al. 2017b), although a combination of collagenase and dispase may be preferable. Moreover, both type II and type IV collagenase can be used to isolate hPDCs and mPDCs. Collagenases are proteases which cleave Pro-X-Gly-Pro sequences between $\mathrm{X}$ and glycine, where $\mathrm{X}$ is a neutral amino acid. This sequence is found with high frequency in collagen. Collagenase is unique among proteases in its ability to degrade the triple-helical native collagen fibrils.

Often, collagenase solutions are mixed with dispase to further enhance the breakdown of the matrix. Dispase is a gentle protease which cleaves fibronectin, collagen type IV, and collagen type I, all of which are present at high levels in the periosteal matrix.

After enzymatic digestion, the duration of which should be optimized, the collagenase-dispase mix is removed by centrifugation, and the cell pellet is resuspended in culture medium (Fig. 3b). It is often not possible to perform a cell count for hPDCs at this point due to their low numbers. Instead, seeded hPDCs should be viewed through a brightfield microscope and cell attachment can be visualized just hours postseeding (Fig. 3c). Within 2-4 h after seeding, most hPDCs adhere to the plastic of the culture plate and begin to display their characteristic spindle-like elongated morphology (Fig. 3d).

In the event where large pieces of debris or cell aggregates are observed, multiple options are available for their removal. Visibly large debris can be removed by passing the lysate through a 70- $\mu \mathrm{m}$ nylon mesh. Aggregates of cells can be dissociated by thoroughly and carefully pipetting the cell suspension with a $1000-\mu 1$ pipette. This step is gentle on the cells, but should only be performed in the absence of debris, to prevent the clogging of the pipette tip. If unsuccessful, deoxyribonuclease I (DNase I) represents a gentle option. DNA released by apoptotic or dead cells increases the viscosity of the sample and can lead to the aggregation of cells. In
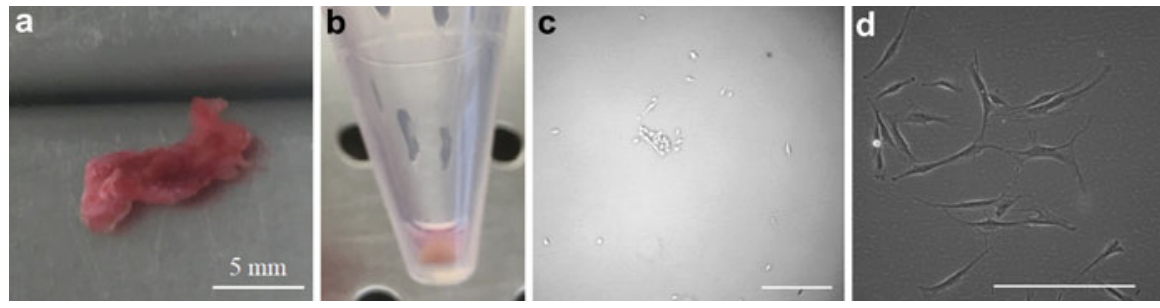

Fig. 3 Steps of PDC isolation. A typical sample of human periosteum as obtained from patients undergoing osteosynthesis or distraction osteogenesis (a). After digestion, the pellet should be clear of RBCs (b). Approximately $12 \mathrm{~h}$ after seeding, nonadherent cells are removed. PDCs typically have an elongated fibroblast-like phenotype, show at $4 \mathrm{X}(\mathbf{c})$ and 10X (d) magnification. Scale bar: $200 \mu \mathrm{m}$. 
cases where high numbers of cell clumps and dead cells are observed, DNase is the recommended next step to try and increase the single cell yield.

As previously mentioned, the periosteum is highly vascularized. It is therefore very well possible that a large amount of cells from the hematopoietic lineage contaminate the sample. The most straightforward way to remove these cells is to wait for the PDCs to adhere and change the medium which contains the plastic nonadherent blood cells. This should be done within $24-48 \mathrm{~h}$ after the start of the culture. If left unchecked, red blood cells (RBCs) will die, which releases reactive oxygen species (ROS) into the culture. NK cells can also have detrimental effects on the culture, as their cytotoxicity is regulated by a balance of stimulatory and inhibitory signals. The culture medium does not support this tightly regulated balance, which therefore results in cytotoxicity towards the hPDCs.

\subsection{In vitro Expansion}

Tissue engineered living implants require large numbers of cells, estimated from 15 to 45 million cells for restoring the joint surface, to over 500 million to bridge a $4 \mathrm{~cm}$ tibia defect (Wakitani et al. 2002) Traditionally, PDCs are expanded in 2D cultures in media supplemented with fetal bovine serum (FBS). Under serumcontaining conditions, hPDCs have shown a remarkable in vitro expansion potential for up to 30 population doublings with a doubling time of approximately 55 hours (Lambrechts et al. 2016). While FBS provides good results in terms of expansion, it has a few drawbacks. First and foremost, it is xenogeneic, which hampers translation to the clinic. Secondly there is major batch-to-batch variability in the composition of FBS. In addition, FBS contains unknown concentrations of numerous biologically active components which are known to interfere with periosteal chondrogenesis, TGF- $\beta 1$ and BMP signaling (Fitzsimmons et al. 2004; Shahdadfar et al. 2005). In recent years, human platelet lysate (hPL) has been suggested as an alternative medium supplement (Astori et al. 2016; Doucet et al. 2005). While hPL also has lot-to-lot variability, it has the advantage of being xeno-free. Pooling of large numbers of donors (20-120) is now being performed to reduce this batch effect (Strunk et al. 2018). One of the most striking differences which can be observed when comparatively culturing hPDCs in FBS- and hPL-supplemented media is the increased proliferation. This observation is consistent for multiple sources of cells originating from the mesenchyme, including the bone marrow, umbilical cord, corneal stroma, and adipose tissue (Ben Azouna et al. 2012; Fazzina et al. 2016; Matthyssen et al. 2017; Reinisch et al. 2007). In addition, hPL-expanded MSCs were reported to have an enhanced osteogenic and chondrogenic differentiation potential (Jonsdottir-Buch et al. 2013; Salvade et al. 2010). To address the issues, with interfering ligands, stimulatory factors, and batch-batch inconsistency, a shift toward alternate supplements and chemically defined media (CDM) has been advocated and intensively investigated (Bolander et al. 2017, 2019).

It is important to stress that PDC culture conditions need to be optimized depending on the source of the periosteum. This entails the basal media, the growth 
factor-containing excipients, and combinations thereof. Human- and sheep-derived PDCs can be efficiently expanded in Dulbecco's Modified Eagle Medium (DMEM) supplemented with $10 \%$ FBS. For hPDCs, this $10 \%$ FBS can be replaced by $10 \%$ hPL, with positive effects on their proliferation and bone-formation capacity (Gupta et al. 2019). Sheep PDCs on the other hand also proliferate faster when cultured with $10 \% \mathrm{hPL}$, but also rapidly become senescent (in-house data, unpublished). DMEM as a basal medium does not support expansion of murine PDCs, where $\alpha$-minimal essential medium is advised as the basal medium of choice (van Gastel et al. 2012).

\subsection{D Culture}

Bioreactor setups have been proposed to increase the scalability of cell therapies. One option for 3D bioreactor culture is the use of spinner flasks with microcarriers. Using collagen-based microcarriers, it was shown that a spinner flask setup with hPL-supplemented medium had multiple advantages: hPDC proliferation speed increased dramatically, while improving the in vivo bone forming capacity, which is a critical parameter in bone tissue engineering. The significant decrease in culture time due to the use of hPL and a 3D-setup is likely to make this strategy more costeffective in the long run (Gupta et al. 2019).

\section{Periosteum Derived Cells in Regenerative Medicine}

In the development of a successful cell-based implant for a critical bone fracture, the first step is to make a clinical characterization of the defect (Fig. 4a). This includes to define the size, stability, complexity (which tissue types are affected), severity of damaged surrounding soft tissue, potential vascularization issues, and identification of the required treatment strategy. This may help to define which regenerative route (e.g., intramembranous or endochondral fracture healing) may be required.

The next step is to define how the implant should be designed to meet critical regulatory and clinical criteria. In critical sized defects or defects with a severely damaged surrounding environment, a cell-based implant may significantly improve the potential timely success of regeneration. Next, biologists can determine which crucial biological processes that are involved in the tissues to be regenerated and define which factors and molecular events are required for the recapitulation thereof based on a the appropriate choice of progenitor cell (Fig. 4b). With a cell-based implant, there are often a critical number of cells that are required to induce differentiation. Therefore, to reach sufficient cell numbers, cell expansion can be carried out according to standard protocols in vitro, or postimplantation in situ. If the latter is chosen, the issues with integration will be limited, but require a sophisticated environment that also induces sufficient steering for differentiation and matrix production. The next step is differentiation strategy, which molecules and 3D environment are required to steer the specific path of differentiation. As a final step, cell and tissue maturation needs to be directed in vitro and the final living 

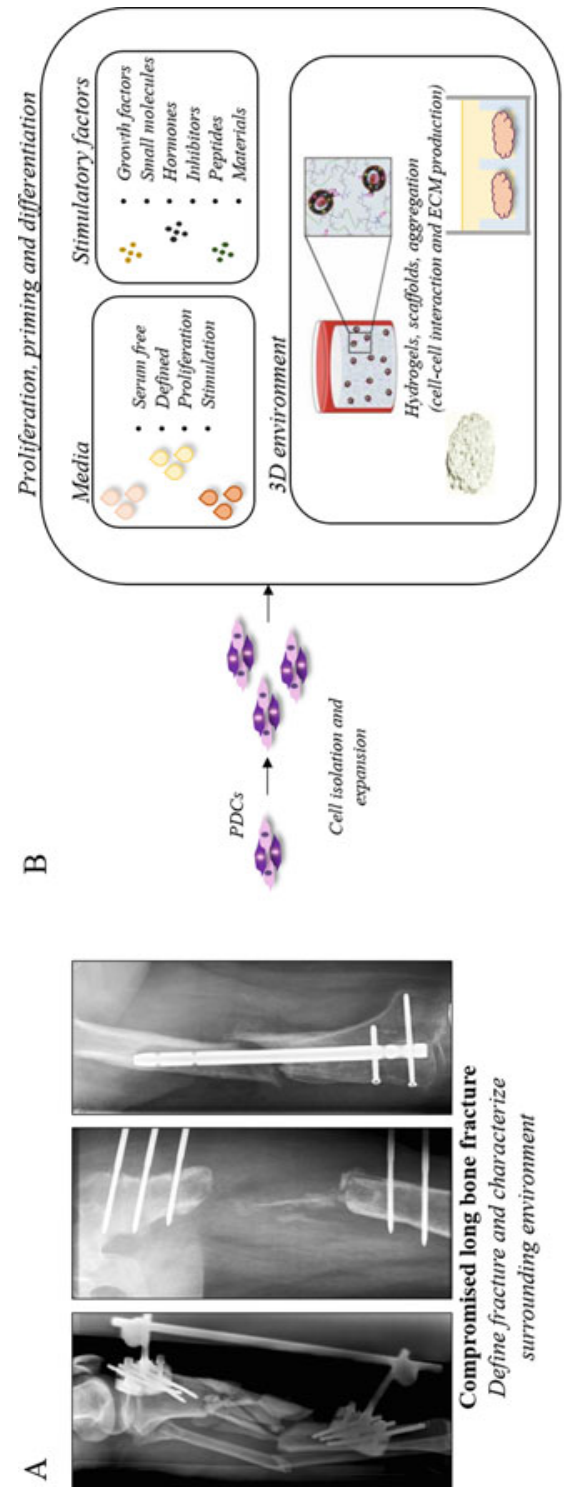

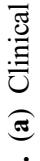

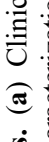

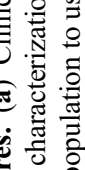

政

可

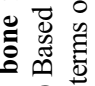

졸

过

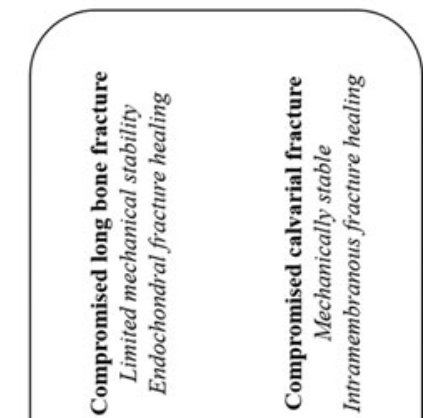

흠 囟

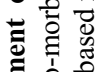

छ

记

Ð 을

อ ․ㅠㅁㅠ

b.

을

害客

ㅎํㅇ 웜

홀

过

产

$\overline{\mathrm{d}} \mathrm{c}$

* क्ञ

$\div \stackrel{\square}{0}$

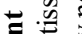

包

立 ट्ट \& है . ธี

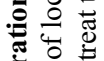
훙 है ¿. 刍 \& . ज记 눙 는

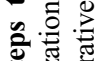
क $\checkmark$ 苋 ㅎํㄴ릉 
tissue intermediates are then assembled for implantation into the fracture site (Fig. 4c). Uniquely, periosteum derived cells are crucial, required, and actively contributing to both intramembranous and endochondral fracture healing and their potential is ideal for the development of skeletal tissue regenerative constructs for the treatment of both direct and endochondral tissue regeneration.

\section{$8 \quad$ Periosteum Derived Cells for Intramembranous Fracture Healing}

The cells provide the driving force in a cell-based construct for regenerative purposes, but their differentiation and matrix secreting potential is stringently depending on the presented micro- and macroenvironment. Due to the complex environment that is represented by the progenitor cells homing niche in vivo, it is a difficult task to create an in vitro equivalent. Consequently, extensive research in terms of development of scaffolds and stimulatory molecules regarding how these affect cell behavior has been carried out. Initially, a scaffold was mainly used for delivering cells to the defect site, but as our understanding of the crucial role of the microenvironment on cell behavior evolved, the surrounding matrix is today almost as important as the cell itself. Scaffolds can be made of natural or synthetic biomaterials. Appropriate carriers for skeletal tissue regeneration, and in particular for long bone fractures should possess osteoconductive and/or osteoinductive properties, while supporting osseointegration. For intramembranous bone formation, $\mathrm{Ca}^{2+}$-based scaffolds have shown to be suitable carriers for periosteum derived cells. In an early in vivo ectopic study in mice, Eyckmans et al. showed that when in vitro expanded human periosteum derived cells (hPDCs) seeded on a Collagraft ${ }^{\mathrm{TM}}$ carrier (an open porous composite made of $\mathrm{CaP}$ granules consisting of $65 \%$ hydroxyapatite (HA) and $35 \%$ $\beta$ - tri-calcium phosphate ( $\beta$-TCP), embedded in a bovine collagen type I matrix), were able to form ectopic bone 8 weeks postimplantation (Eyckmans et al. 2010). In order to understand the osteoinductive effect of CaP-based materials on hPDCs, the mechanisms of action were investigated. It was shown that the de novo bone was mainly formed by the hPDCs, and the process required $\mathrm{Ca}^{2+}$ in the scaffold to initiate the osteoinductive program in the implanted cells. Moreover, inhibition of endogenous bone morphogenetic protein and Wnt signaling by overexpression of the secreted antagonists Noggin and Frzb, respectively, also abrogated osteoinduction. Further, it was shown that proliferation of the engrafted hPDCs was strongly reduced in the decalcified scaffolds or when seeded with adenovirus-Noggin/Frzb transduced hPDCs. This indicated that cell division/proliferation of the engrafted hPDCs was

Fig. 4 (continued) cell expansion, what medium is needed, proliferative and differentiationinducing factors, and what kind of $3 \mathrm{D}$ environment is favorable? (c) Then these factors are combined in the development of a cell-based construct for the treatment of the critical defect 
required for direct bone formation. It can be hypothesized that this would not be required with higher cell seeding numbers. However, higher seeding densities did not improve bone formation, implicating that higher cell numbers may limit availability of nutrients thus jeopardize the survival of implanted cells. Lower seeding number on the other hand allows the cell to proliferate to reach the required cell density in the implant, prior to the onset of differentiation.

Subsequently, enhanced in vitro differentiation prior to in vivo implantation of the same progenitor cell population was studied to improve bone formation. For this, hPDCs were seeded on Collagraft ${ }^{\mathrm{TM}}$ scaffolds (calcium phosphate rich matrix or CPRM) or on decalcified scaffolds (calcium phosphate depleted matrix or CPDM), followed by subcutaneous implantation in nude mice to trigger ectopic bone formation. In this system, CPRM, but not CPDM scaffolds that lacked $\mathrm{Ca}^{2+}$, supported osteoblast differentiation and bone formation by the seeded hPDCs. Microarray gene expression analysis at $20 \mathrm{~h}$ after seeding, and 2, 8, and 18 days after implantation showed that both matrices triggered a similar gene expression cascade. However, gene expression dynamics progressed faster in CPRM scaffolds compared to CPDM scaffolds. The difference in transcriptional dynamics was associated with differential activation of hub genes and molecular signaling pathways related to calcium signaling (CREB), inflammation (TNF $\alpha, N F-k B$, and IL-6), and bone development (TGF $\beta$, $\beta$-catenin, BMP, EGF, and ERK signaling). Starting from this set of pathways, a growth factor cocktail was developed that could enhance osteogenic differentiation in vitro and in vivo bone formation through the intramembranous pathway. With the key factors required for $\mathrm{CaP}$-induced bone formation by hPDCs identified, the effect of the specific characteristics of the CaP-material was assessed next. CaP naturally exists in bone as hydroxyapatite, but can also be used as a synthetic or partly synthetic material. Interestingly, it was shown that scaffolds containing natural hydroxyapaptite were more beneficial for bone formation, compared to fully synthetic materials in combination with hPDCs (Roberts et al. 2011).

The unknown mechanism by which natural biomaterials showed improved osteoinductive properties when seeded with hPDCs in comparison with synthetic materials has hampered the optimization of novel biomaterials suitable for the clinical setting. It was recently shown that this may be due to a different activation of the innate immune system (Sadtler et al. 2019). Therefore, further knowledge regarding how these different materials activate the early molecular events governing bone tissue formation by hPDCs was required. For this, hPDCs were combined with three types of clinically used CaP-scaffolds to obtain constructs with a distinct (high-natural HA), moderate (partly natural HA), and no (synthetic HA) bone forming capacity in combination with hPDCs in vivo. Protein phosphorylation together with mRNA transcript analysis for key ligands and target genes was investigated 24 hours post-cell seeding in vitro and 3 and 12 days post-ectopic implantation in nude mice. A computational modeling approach was used to deduce critical factors and the level of activation that was required for bone formation 8 weeks postimplantation. Interestingly, the combined $\mathrm{Ca}^{2+}$-mediated activation of BMP-, Wnt-, and PKC signaling pathways 3 days post implantation was able to discriminate the bone forming from the nonbone forming constructs. Subsequently, a 
mathematical model able to predict in vivo bone formation by hPDCs with $96 \%$ accuracy was developed. These results illustrated the importance of defining and understanding key CaP-activated signaling pathways required for in vivo bone formation. With this information, it was clear that hPDCs can be robustly steered towards in vivo intramembranous bone formation when seeded onto CaP-based carriers with appropriate characteristics. However, the intramembranous bone forming process is slow and routinely only generates limited amounts of bone and bone marrow by the implanted cells. In a complex environment such as a large fracture, it is crucial to get a bridging between the bone ends for successful healing. Consequently, the endochondral route may be of greater value as a target for the typical complex bone fractures requiring treatment in the form of a cell-based construct.

\section{Periosteum Derived Cells for Endochondral Fracture Healing}

Periosteum derived cells have been shown to be crucial in long bone fracture healing due to their contribution to both the intramembranous and endochondral bone healing process. Furthermore, their activation is to a large extent initiated and steered by members of the BMP-family (Salazar et al. 2019; Tsuji et al. 2006). In an attempt to enhance and steer the bone forming capacity of hPDC-CaP-constructs towards the endochondral pathway, the osteochondrogenic response of BMP-ligands with a known role in fracture repair has been evaluated in vitro (Bolander et al. 2016). BMP-2, -4, -6, and -9 were shown to induce in vitro differentiation of hPDCs. Subsequently, these ligands were coated onto clinically approved CaP-scaffolds with limited (BioOss ${ }^{10}$ ) or no (CopiOs ${ }^{10}$ ) bone forming capacity followed by seeding with hPDCs. Protein lysates and conditioned media were investigated for activation of BMP signaling pathways $24 \mathrm{~h}$ post seeding. Upon in vivo implantation, the most abundant bone formation was found in BMP-2 and BMP-6-coated scaffolds 8 weeks postimplantation. Interestingly, implanted cells actively contributed to the newly formed bone and remnants of cartilage could be observed in BMP-coated CopiOs constructs. This confirmed the synergistic effect of combined CaP and BMP stimulation for bone formation by hPDCs. Interestingly, computational analysis displayed that the type of BMP-ligand as well as the specific CaP-scaffold affects skeletal tissue formation, observed in a qualitative as well as quantitative manner (Bolander et al. 2016).

From the BMP-family members, BMP-2 and BMP-7 were the first to obtain approval for clinical applications. However, their use has been associated with unpredictable bone formation. This has been attributed to a number of factors including the delivery of supraphysiological levels of BMPs and insufficient progenitor cells in the damaged fracture environment (Pobloth et al. 2015; Shields et al. 2006). In vitro primed cell-based regenerative constructs could overcome this hurdle by delivering the crucial number of appropriately primed cells in vitro to regenerate the damaged tissue in vivo. However, in vitro stimulation of progenitor cells for 
in vivo tissue regeneration is challenging. Long-term in vitro stimulated cells often fail to integrate with the host, likely due to the maturity of the tissue (Yamashita et al. 2015). Shorter priming periods on the other hand do not seem to be sufficient in terms of clinically relevant results (Eyckmans et al. 2013). A potential reason for this can be that the in vitro priming is carried out in media containing serum (Ryan 1979). Indeed, serum contains an undefined and variable range of factors such as cytokines and inhibitors that bind to cell surface receptors. In consequence, batch-to-batch variability significantly affects the characteristics of cell-based implants, leading to unpredictable behavior and outcomes (Baker 2016; Jung et al. 2012). Since stimulatory ligands bind to cell surface receptors which may be occupied by factors in the serum, a serum free preconditioning of hPDCs prior to growth factor treatment was hypothesized to improve the cellular response. Consequently, a preconditioning regime of hPDCs in serum free chemically defined media (CDM) was developed which led to adapted progenitor cell subpopulations with improved osteochondrogenic differentiation capacity (Bolander et al. 2017). This phenotype shift was marked by reduced positivity for CD105 but enhanced positivity for CD34 together with elevated mRNA transcript expression of marker genes such as FGF2, VEGF, and BMP type 1 and 2 receptors. The preconditioned hPDCs was then assembled into microspheroids in order to mimic the cellular condensations preceding endochondral fracture healing and by providing biomimetic 3D cues. The microsperoids were simultaneously treated with BMP-2 under serum free conditions, and cell specification towards the osteochondrogenic lineage was observed in vitro (Bolander et al. 2017). Interestingly, physiologically relevant levels of autocrine and paracrine growth factors were secreted by the fate-steered engineered microtissues. In vivo, the self-sustained implant proceeded to form bone in the ectopic setting and was able to regenerate a critical size long bone defect in mice through the endochondral pathway. Interestingly, the implanted cells largely contributed to the formation of the initial cartilaginous callus at week 4 and to the immature bone at week 4 , but less to the remodeled mature bone at week 8 . These findings suggest that the major impact of the implanted cells occurs in the early phase and aids in the recruitment of cells from the host environment that subsequently aid in the later stage remodeling phase.

In a similar approach, periosteum-based microspheroids were used for the scalable production of a larger implant, developed through the assembly by fusion between the microspheroids after 7, 14, 21, or 28 days of in vitro differentiation in a growth factor cocktail consisting of standard low glucose growth medium supplemented with ascorbate-2 phosphate, dexamethasone, proline, Rho-kinase inhibitor Y27632, ITS+, BMP-2, GDF5, TGF- $\beta 1$, BMP-6, and basic FGF-2 (Nilsson Hall et al. 2020). It was shown that a significant maturation of the microspheroids took place between day 14 and 21, reflected by elevated expression of FOXA2, DMP1, and SCIN which are crucial for chondrocyte hypertrophy (Ionescu et al. 2012), cartilage--bone transition (Ye et al. 2005), and bone resorption (Song et al. 2015), respectively. In vivo, histology and immunohistochemistry was used to distinguish between the day 14 and day 21 samples as "early prehypertrophic" stage for day 14, and "late prehypertrophic" stage for day 21 modules. Based on these findings, microspheroids from day 21 were used as microtissues to fuse in a 
mold design to mimic the critical size defect in a nude mouse model. Upon implantation, the macrostructure was able to heal the defect through endochondral bone formation. The regenerated and remodeled bone exhibited already after 8 weeks similar morphological properties to those of native tibia. The significance of these research findings lies in the ability to use the microspheroids as a living "bioink" allowing bottom-up manufacturing of multimodular tissues with complex geometric features and specified quality attributes.

In an attempt to further understand the improved regenerative potential by serum free preconditioning of hPDCs, in depth profiling by single-cell RNA sequencing was performed (Bolander et al. 2019). Interestingly, preconditioning in CDM was shown to induce a phenotype switch at the single-cell level with elevated expression of markers and signaling clusters associated with skeletal system development, tissue regeneration, stem cell maintenance, cell fate commitment, and the BMP-signaling pathway. In a comparative analysis between cells in serumcontaining growth medium (GM) and CDM by clustering of the complete data set, it was shown that the individual clusters from CDM origin displayed elevated markers and processes associated with native osteochondral progenitor cells. On the other hand, the majority of the GM-originated clusters were more heterogeneous, with subpopulations enriched for markers related to connective tissue as well as chondrogenic and osteogenic progenitors. These findings once again confirmed the more homogenous and osteochondro-specific progenitor commitment of the CDM subpopulation. Detailed analysis on the inferred transcription factor activity linked upregulated and active involvement of the SOX4, SOX9, MSX1, and RUNX2 regulons with the enhanced bone forming potential in the CDM population. Of note, these data were in line with recent findings mapping the hierarchy of human skeletal stem and progenitor cells present in the human fetus, but also activated during postnatal fracture repair (Chan et al. 2018). Specifically, it is of great importance that a similar progenitor cell program can be activated after extensive in vitro expansion, a phenomenon known to reduce the progenitor cell potential in the presence of serum.

Furthermore, when the serum-free preconditioned cells were primed with BMP-2 under serum-free conditions for an additional 6 days in vitro, and then seeded onto the CopiOs ${ }^{\circledR}$ carrier followed by in vivo implantation, enhanced bone formation was seen in comparison to cells cultured under serum-containing conditions. In order to define a marker for the cell population with enhanced bone forming capacity, BMP-receptor expression was investigated on the protein level due to the indispensable role of BMP-ligands as stimulatory factors in the periosteum during fracture healing (Salazar et al. 2019). BMP-ligands signal through a complex of type 1 (ALK1/ACVRL1, ALK2/ACVR1, ALK3/BMPR1A, ALK6/BMPR1B) and type 2 (BMPR2, ACVR2A, and ACVR2B) transmembrane serine/threonine kinase receptors. As such, the expression level and availability of the BMP-receptors on a progenitor cell are of relevance for their ability to respond and undergo subsequent differentiation upon BMP-stimulation (Salazar et al. 2016). Unfortunately, this part is an often neglected parameter in the preparation and characterization of cell-based constructs. Instead, current progenitor markers are selected based on the cell's ability 
to proliferate and differentiate under nonphysiological conditions (International Stem Cell Initiative et al. 2010; Verbeeck et al. 2019).

Initially, the expression of BMP-receptors was investigated by mRNA transcript analysis and on the protein level by flow cytometry. Encouragingly, all investigated receptors including ALK2, ALK3, ALK6 and BMPR2 were confirmed to be upregulated upon serum-free preconditioning both in terms of number of positive cells, but also in number of receptors per cell. However, a specifically drastic increase was seen for BMPR2, which was therefore selected for further investigation. When sorting for BMPR2 ${ }^{+}$cells, elevated bone forming capacity was confirmed even with reduced cell numbers. In addition, silencing of BMPR2 abrogated fracture healing in an orthotopic mouse model for a critical size defect. Interestingly, the improved cell differentiation seen in the serum-free preconditioned hPDCs was associated with a cellular switch towards a more efficient metabolism, potentially related to the elevated resistance to harsh conditions as encountered during in vivo implantation. These findings support the importance of the appropriate design and development of cell-based constructs.

In terms of biomaterial for endochondral tissue formation by hPDCs, CaP-based materials have shown to be suitable in combination with BMPs. In addition, polyethylene glycol (PEG) hydrogels functionalized with the cell-binding motif Arginine-Glycine-Aspartic Acid (RGD) have been confirmed to support proliferation, chondrogenic gene expression, and matrix production of encapsulated hPDCs (Kudva et al. 2018). In growth medium, the hPDCs in the RGD-functionalized hydrogels maintained high levels of viability and demonstrated an enhanced proliferation when compared with hPDCs in nonfunctionalized hydrogels. Additionally, the RGD-containing hydrogels promoted higher glycosaminoglycan (GAG) synthesis and chondrogenic gene expression of the encapsulated hPDCs, as opposed to the nonfunctionalized constructs, when cultured in two different chondrogenic media. These results demonstrated the potential of hPDCs in combination with enzymatically degradable PEG hydrogels functionalized with adhesion ligands for cartilage regenerative applications. Interestingly, the chondrogenic phenotype in the encapsulated hPDCs could be further enhanced upon the addition of TGF- $\beta$ releasing beads (Kudva et al. 2019).

\section{Osteochondral Tissue Repair by Periosteum Derived Cells}

Human periosteum derived cells have also been used for osteochondral tissue repair. In vitro expanded periosteal cells were seeded in micromass cultures and simultaneously stimulated with a growth factor cocktail comprising transforming growth factor (TGF)- $\beta 1$, BMP-2, growth differentiation factor (GDF)5, BMP6, and fibroblast growth factor (FGF)2 for 28 days (Mendes et al. 2018). To evaluate in vivo tissue formation by the in vitro treated micromass cultures, they were implanted ectopically in nude mice and orthotopically in critical-size osteochondral defects in nude rats followed by evaluation through microcomputed tomography $(\mu \mathrm{CT})$ and immunohistochemistry. mRNA transcript analysis after 28 days of in vitro culture 
revealed the expression of early and late chondrogenic markers and a significant upregulation of NOGGIN as compared to human articular chondrocytes. Histological examination revealed a bilayered structure comprising of chondrocytes at different stages of maturity. Ectopically, the implanted tissues generated both bone and mineralized cartilage at 8 weeks post implantation. Osteochondral defects treated with the in vitro stimulated cells displayed glycosaminoglycan (GAG) production, type-II collagen, and lubricin expression. Immunostaining for human nuclei suggested that hPDCs contributed to the repair of both the subchondral bone and articular cartilage. This study was the first to use periosteal cells for stable cartilage formation. Due to their fate towards the osteogenic and endochondral lineage, it is hypothesized that PDCs would not be able to form articular cartilage and it is not yet clear why the in vitro primed tissues formed bone in the ectopic setting, while it formed articular cartilage when implanted in the osteochondral defect in the joint. This suggests that the differentiation events depend on their specific location and thus environmental cues. However, it remains to be evaluated how these implants perform in a larger animal model with a more clinically relevant load, as well as in a long term study.

\section{Periosteal Cells in the Preclinical Setting}

Rodents represent the most commonly utilized models to evaluate the in vivo behavior of in vitro engineered cell-based implants. Even though they fill an important purpose to deliver Proof of Concept as a screening model, obtained results are largely biased since the small scale generally avoids issues with nutrient depletion and upscaling. Therefore, larger animals are required prior to clinical translation and a summary of some reported models and their advantages and disadvantages are presented in Table 2.

In general, larger animal models are solely used as orthotopic models and can from a surgical point of view in the field of skeletal tissue engineering be categorized as (1) calvarial defect, (2) segmental long bone defect, and (3) osteochondral defect, all three with different critical size highly depending on location, age of animal and species. The calvarial defect provides a good nonloading bone healing environment with relative biological inertness due to poor blood supply and limited access of bone marrow. This is essential since the model is aimed to resemble the atrophic mandibular/craniofacial bone in humans. Furthermore, it provides a suitable large scale environment to study the design of implants to follow the intramembranous ossification route. The standard rodent calvarial bone defect is typically created by using a trephine drill that makes a circular defect in the cranial skeleton on the midline (Szpalski et al. 2010). However, the reliability of the model is highly depending on the precision of the sagittal suture and careful protection of the dura mater underlying the defect, important for the healing of the cranial skeleton. Furthermore, the filling materials should be strong and resistant enough to avoid the dilation of brain tissue beneath the defect (Ji et al. 2012). The use of periosteal cells for the treatment of a calvarial defect in a porcine model was utilized in a study 


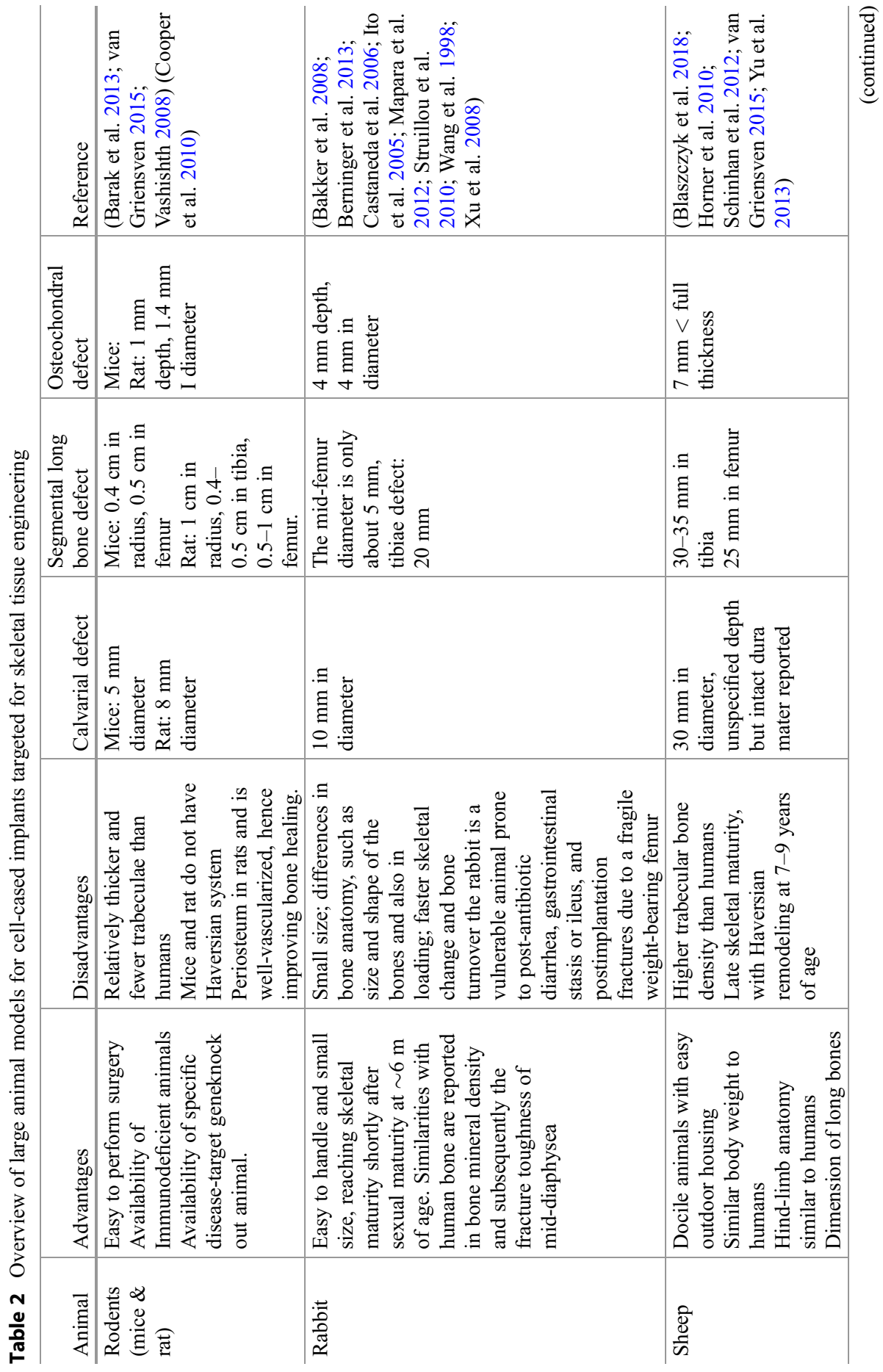




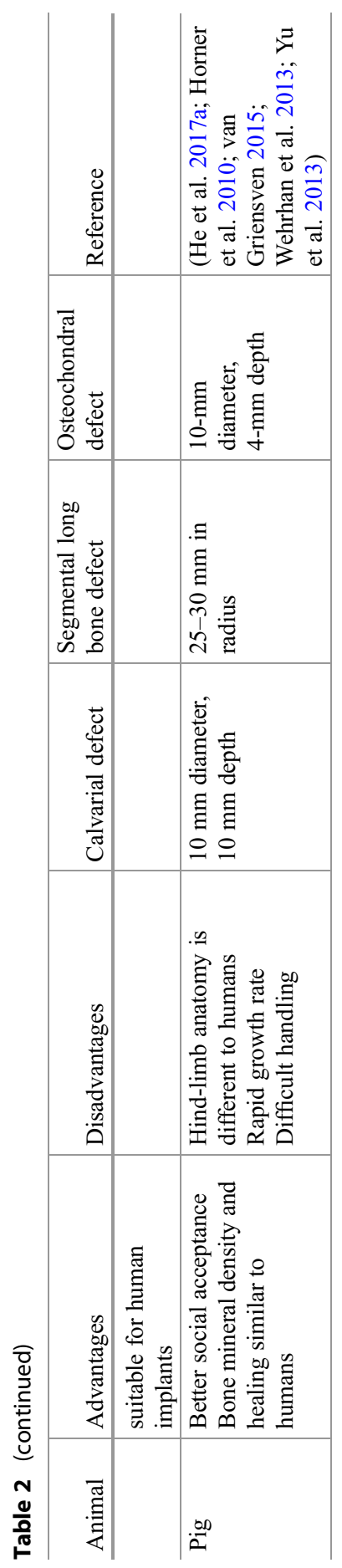


with the goal to investigate the bone forming potential of progenitor cells from adipose, bone marrow, and periosteal tissue (Stockmann et al. 2012). Autologous progenitor cells were harvested and expanded in vitro to reach sufficient cell numbers. Thereafter, cells were seeded onto collagen scaffolds of low cross-linked bovine collagen type I and cultured for osteogenic differentiation in the presence of osteogenic induction medium for another 7 days. Then, a coronal-sagittal approach was used in the forehead region of the pig and cylindrical defects of $1 \mathrm{~cm}$ in depth and $1 \mathrm{~cm}$ in diameter were created. The internal plate of the neurocranium remained completely intact during the procedure and the cell-seeded scaffolds were subsequently implanted into the fresh monocortical calvarial bone defects. At 90 days, the majority of defects treated with autologous cells showed complete osseous regeneration but the control defects without implanted cells did not demonstrate bone healing. Off note, no difference in bone regeneration induced by the different cell population was noted (Stockmann et al. 2012).

Segmental long bone defects on the other hand allow researchers to test and understand the regenerative implants destined for long bones. The creation of segmental long bone defects is usually performed through an osteotomy approach utilizing a drill or saw to surgically remove the required length of bone from a predetermined site, producing a consistent defect in all subjects. The bone itself can be fixed internally with either bone plates, intramedullary rods (Horner et al. 2010) or by an external fixator such as the Ilizarov fixation technique (Lammens et al. 1998). Equally important as fixation is the specific segmental model in terms of defect environment. Bone regeneration is an area where biology is directly correlated with geometric and mechanical conditions, and combined play an indisputable role which needs to be taken into account in translational research. The segmental bone defect models is often used to evaluate implants developed for the treatment of nonunion bone fractures, representing a highly avascular environment filled with fibrotic tissue. Therefore, it is important that not only the defect size, but also the surrounding environment represent a clinically relevant setting. Since this is often a neglected factor, clinical translation remains a considerable challenge, in particular since robust outcomes in well-defined large animal models are lacking. In an attempt to develop a reliable model of a nonunion defect (pseudoarthrosis), skeletal immature and mature sheep were evaluated with tibial bone defects of both 3.0 and $4.5 \mathrm{~cm}$ in immature and $4.5 \mathrm{~cm}$ in mature animals (Lammens et al. 2017). The size of the defects was selected based on the guidelines that critical size defects should be at least 2 to 2.5 times the diameter of the bone. According to these guidelines, a $3 \mathrm{~cm}$ defect should be made in the skeletal immature sheep and a $4.5 \mathrm{~cm}$ defect in the skeletal mature. Upon defect creation, gaps were left empty during a period of 6 weeks to allow ingrowth of fibrotic scar tissue that was subsequently removed for the implantation of a cement spacer for another 6 weeks to induce a Masquelet membrane (Masquelet and Begue 2010). After the 6 weeks of membrane induction, $6 / 12$ of the young sheep with a $3 \mathrm{~cm}$ defect showed of $50 \%$ bone filling up the defect area. In the group of $4.5 \mathrm{~cm}$ defect of skeletal immature sheep, some bone formation was seen in 5/20 animals. While no bone formation was seen in the $4.5 \mathrm{~cm}$ defect in skeletal mature animals. Combined these data confirms that not only the size of the 
defect, but also the age of the animal and the surrounding environment play a crucial role in the selection of a suitable animal model for preclinical testing.

A more straight forward sheep model of critical sized middiaphyseal femur defects was used to evaluate an engineered periosteal substitute, intended for the treatment of a critical sized long bone defect after tumor resection (Knothe Tate et al. 2011). The periosteal substitute consisted of an isotropic elastomer alone, the isotropic elastomer with collagen membranes, the isotropic elastomer with a collagen membrane and autologous periosteal cells or the elastomer with autologous periosteal strips. Upon the creation of $2.54 \mathrm{~cm}$ segmental defects in the middiaphyseal femur, the $3.5 \mathrm{~cm}$ long periosteal substitutes designed to overlap $0.5 \mathrm{~cm}$ distal and proximal to the defect were immediately implanted with a $5 \mathrm{~mm}$ overlap with the native periosteum. Bone formation was evaluated by micro-CT and histomorphometry after 3 and 16 weeks post implantation. Improved fracture regeneration was seen in the groups with membranes incorporating periosteal factors (cells or strips) as compared to isotropic control membranes made of the same material or membranes with only collagen strips. Quantification based on histological evaluation further confirmed an improved bone regeneration in membranes containing the full periosteal strips in comparison to the periosteal cells. Consequently, these data suggests that not only the periosteal progenitor cells, but also the periosteal niche as such is important for the regenerative potential of the periosteum. These findings are in line with recent literature where the periosteal homing in mice was studied and specifically the matrix protein periostin was identified as crucial for the regenerative potential of periosteal cells (Duchamp de Lageneste et al. 2018).

\section{Clinical Evaluation of Periosteal Cells}

The quest to identify and characterize the different progenitor cell populations present in the periosteum may just have started, but their unique capabilities have already brought them to the clinical setting. Upon conducting a search for clinical trials containing the keywords periosteum/periosteal, seven trials can be found. Five of these are already completed, one is recruiting and a final study is yet to be started (Clinicaltrials.gov 2019). In a completed study from 2018, the aim was to evaluate the possible benefit on wound healing and flap stability of a periosteum inclusion, comparing a "split-full-split" thickness flap elevation versus a "split" thickness approach for the treatment of isolated-type gingival recessions in the upper jaw. In another completed study from 2007, the use of periosteum versus bone fixation was evaluated in forehead lift. In this procedure, variable methods of fixation have been described with different rates of success. In a third completed study from 2008, an arthroscopic-assisted posterior cruciate ligament (PCL) reconstruction was performed using a femoral knot/press-fit technique with a periosteum-enveloping graft in a tibial tunnel. The investigators evaluated the results of patients with PCL ruptures, who underwent PCL reconstruction using this unique technique. In a study from 2015, a study directed towards the evaluation of two autogenous regenerative materials, marginal periosteal pedicle graft (MPP) and platelet rich fibrin (PRF) as 
membrane barriers for treating intrabony defects was evaluated. This study was conducted due to the periosteum's reported significant clinical outcomes, but the limited availability of the periosteum makes it necessary to evaluate other autogenous alternatives such as PRF that could offer predictable outcomes. In another study completed 2014, clinical and radiographic evaluation of autogenous periosteal pedicle graft in comparison with collagen membrane for management of periodontal intrabony defects was evaluated. Encouragingly, the periosteal group showed reduced defects at 6 months post treatment. Unfortunately, apart from this study, no results are posted in any of the other completed studies. In another currently recruiting study, periosteum in the recession defect site for gingival recession will be used as an autologous graft after raising a flap and the results will be compared with a group treated by the current standard treatment, coronally advanced flap with subepithelial connective tissue graft. In the final study that is a prospective interventional study yet to start recruitment, the effectiveness of a periosteal pedicle will be evaluated and compared as grafting technique in combination with an egg shell derived nano hydroxyapatite as regenerative graft material for regeneration of intrabony defects. In a currently active study, evaluation of the clinical efficacy and safety of autologous osteo-periosteal cylinder graft transplantation for Hepple $\mathrm{V}$ osteochondral lesions of the talus is done. Half of participants will receive autologous osteo-periosteal cylinder graft transplantation, while the other will receive osteochondral graft transplantation as a control group.

In conclusion, the completed, currently ongoing or planned studies using periosteum covers a broad range of conditions as well as treatments. Even though the first study was completed in 2008, it was only in recent years that the number of studies has started to increase. This may be linked to the increasing general knowledge of the periosteum and the potency of the progenitor cells within. However, it is surprising that there are currently no studies registered for the treatment of critical size bone fractures, or periosteum derived cell-based implants for critical bone defects. Since commonly, all registered studies used the periosteum as a tissue, rather than the isolated and expanded cells. When searching PubMed in December 2019 with the keyword "periosteum" 8798 articles are found, while 10,003 articles show up with "periosteal" as a keyword. In addition, when searching for "periosteal cells" 2022 articles are found, while 533 are found on the search of "periosteum derived cells." These search results suggest that the use of periosteum derived cells is still limited and mainly restricted to research laboratories. However, with the increasing knowledge regarding their unique potential, their role in tissue engineering strategies will most likely increase.

\section{The Potential of Periosteum Derived Cells as In vitro Models to Evaluate Treatments for Specific Patients}

The field of cancer biology is in general a great inspiration for regenerative medicine. In cancer, a small population of cells self-renew to replenish the growing cancer. In order to eliminate the disease, these proliferating cells need to be eliminated. To 
achieve this, it requires that the specific mother cell is identified, the proliferative mechanism needs to be understood and a treatment that stops the proliferation of the specific cell, in the explicit setting, could be developed for an effective treatment. For this, patient specific models have been created in order to define personalized treatment (Aleman and Skardal 2019). A similar personalized medicine approach was used to define a treatment alternative to rescue Fibroblast Growth Factor Receptor (FGFR)3 skeletal dysplasia phenotypes through the generation of patient-specific induced pluripotent stem cells (iPSCs) which functioned as in vitro models in the identification of a suitable treatment (Yamashita et al. 2014). Even though iPSCs represent a great in vitro model since their (epi)-genetic memory remains, the generation of iPSCs requires a long culture period, the process is not very efficient and costly, and safety issues remain. Combined, these factors limit their use as a cell-population for a regenerative implant. However, in vitro models could be very interesting when the goal is to target the intrinsic repair mechanisms by the recruitment of endogenous stem/progenitor populations into damaged tissue followed by cell proliferation, differentiation and tissue metabolic activity (Luyten and Roberts 2018). By understanding how the patients cells respond to specific treatments in vitro, the in vivo outcome can me optimized with increased potential for success (Aleman and Skardal 2019). For this, a small sample of their periosteum would be sufficient to optimize a suitable treatment based on the status of their periosteal cells, their cell surface markers, and potential mutations that can be characterized in vitro, prior to in situ intervention.

\section{Conclusions}

Regenerative constructs that mimic our body's natural regenerative system represent an attractive strategy for restoring the function of damaged organs or tissues where currently no reliable treatment is available (Ho-Shui-Ling et al. 2018; Langer and Vacanti 1993; Ma et al. 2014). Key in the construct's success lies in a bioinspired design, typically using appropriate and potent progenitor cells, which upon proliferation and differentiation into tissue intermediates direct tissue repair in vivo together with the available host environment to facilitate integration (Ingber et al. 2006; Lenas et al. 2009a). It is clear that periosteum derived progenitor cells play a crucial role in bone development, maintenance, and fracture healing. Recent progress made in the field of periosteal progenitor cell identification has begun to unravel the specific populations available, and with this information, treatments to target these to direct in vivo tissue formation have only just begun. Based on this, periosteum derived cells represent a very attractive cell source in the development of in situ treatment strategies or cell-based constructs for (large) skeletal defects. 


\section{References}

Agata H, Asahina I, Yamazaki Y, Uchida M, Shinohara Y, Honda MJ, Kagami H, Ueda M (2007) Effective bone engineering with periosteum-derived cells. J Dent Res 86:79-83

Aleman J, Skardal A (2019) A multi-site metastasis-on-a-chip microphysiological system for assessing metastatic preference of cancer cells. Biotechnol Bioeng 116:936-944

Allen MR, Hock JM, Burr DB (2004) Periosteum: biology, regulation, and response to osteoporosis therapies. Bone 35:1003-1012

Almeida CR, Caires HR, Vasconcelos DP, Barbosa MA (2016) NAP-2 secreted by human NK cells can stimulate mesenchymal stem/stromal cell recruitment. Stem Cell Rep 6:466-473

Ambrosi TH, Longaker MT, Chan CKF (2019) A revised perspective of skeletal stem cell biology. Front Cell Dev Biol 7:189

Archer CW, Dowthwaite GP, Francis-West P (2003) Development of synovial joints. Birth Defects Res C Embryo Today 69:144-155

Astori G, Amati E, Bambi F, Bernardi M, Chieregato K, Schafer R, Sella S, Rodeghiero F (2016) Platelet lysate as a substitute for animal serum for the ex-vivo expansion of mesenchymal stem/ stromal cells: present and future. Stem Cell Res Ther 7:93

Baker M (2016) Reproducibility: respect your cells! Nature 537:433-435

Bakker AD, Schrooten J, van Cleynenbreugel T, Vanlauwe J, Luyten J, Schepers E, Dubruel P, Schacht E, Lammens J, Luyten FP (2008) Quantitative screening of engineered implants in a long bone defect model in rabbits. Tissue Eng Part C Methods 14:251-260

Barak MM, Lieberman DE, Hublin JJ (2013) Of mice, rats and men: trabecular bone architecture in mammals scales to body mass with negative allometry. J Struct Biol 183:123-131

Baryawno N, Przybylski D, Kowalczyk MS, Kfoury Y, Severe N, Gustafsson K, Kokkaliaris KD, Mercier F, Tabaka M, Hofree M et al (2019) A cellular taxonomy of the bone marrow stroma in homeostasis and leukemia. Cell 177:1915-1932 e1916

Ben Azouna N, Jenhani F, Regaya Z, Berraeis L, Ben Othman T, Ducrocq E, Domenech J (2012) Phenotypical and functional characteristics of mesenchymal stem cells from bone marrow: comparison of culture using different media supplemented with human platelet lysate or fetal bovine serum. Stem Cell Res Ther 3:6

Berninger MT, Wexel G, Rummeny EJ, Imhoff AB, Anton M, Henning TD, Vogt S (2013) Treatment of osteochondral defects in the rabbit's knee joint by implantation of allogeneic mesenchymal stem cells in fibrin clots. J Vis Exp JoVE 75:e4423

Bianco P, Robey PG (2015) Skeletal stem cells. Development 142:1023-1027

Bianco P, Cao X, Frenette PS, Mao JJ, Robey PG, Simmons PJ, Wang CY (2013) The meaning, the sense and the significance: translating the science of mesenchymal stem cells into medicine. Nat Med 19:35-42

Bjurholm A, Kreicbergs A, Terenius L, Goldstein M, Schultzberg M (1988) Neuropeptide Y-, tyrosine hydroxylase- and vasoactive intestinal polypeptide-immunoreactive nerves in bone and surrounding tissues. J Auton Nerv Syst 25:119-125

Blaszczyk B, Kaspera W, Ficek K, Kajor M, Binkowski M, Stodolak-Zych E, Grajoszek A, Stojko J, Bursig H, Ladzinski P (2018) Effects of polylactide copolymer implants and platelet-rich plasma on bone regeneration within a large calvarial defect in sheep. Biomed Res Int 2018:4120471

Bocker W, Docheva D, Prall WC, Egea V, Pappou E, Rossmann O, Popov C, Mutschler W, Ries C, Schieker M (2008) IKK-2 is required for TNF-alpha-induced invasion and proliferation of human mesenchymal stem cells. J Mol Med 86:1183-1192

Bolander J, Ji W, Geris L, Bloemen V, Chai YC, Schrooten J, Luyten FP (2016) The combined mechanism of bone morphogenetic protein- and calcium phosphate-induced skeletal tissue formation by human periosteum derived cells. Eur Cell Mater 31:11-25

Bolander J, Ji W, Leijten J, Teixeira LM, Bloemen V, Lambrechts D, Chaklader M, Luyten FP (2017) Healing of a large Long-bone defect through serum-free in vitro priming of human periosteum-derived cells. Stem Cell Rep 8:758-772 
Bolander J, Herpelinck T, Chaklader M, Gklava C, Geris L, Luyten FP (2019) Single-cell characterization and metabolic profiling of in vitro cultured human skeletal progenitors with enhanced in vivo bone forming capacity. Stem Cells Transl Med 9(3):389-402

Broos K, Feys HB, De Meyer SF, Vanhoorelbeke K, Deckmyn H (2011) Platelets at work in primary hemostasis. Blood Rev 25:155-167

Caplan AI (1991) Mesenchymal stem cells. J Orthop Res 9:641-650

Castaneda S, Largo R, Calvo E, Rodriguez-Salvanes F, Marcos ME, Diaz-Curiel M, HerreroBeaumont $\mathrm{G}$ (2006) Bone mineral measurements of subchondral and trabecular bone in healthy and osteoporotic rabbits. Skelet Radiol 35:34-41

Chan CK, Seo EY, Chen JY, Lo D, McArdle A, Sinha R, Tevlin R, Seita J, Vincent-Tompkins J, Wearda $T$ et al (2015) Identification and specification of the mouse skeletal stem cell. Cell 160:285-298

Chan CKF, Gulati GS, Sinha R, Tompkins JV, Lopez M, Carter AC, Ransom RC, Reinisch A, Wearda T, Murphy M et al (2018) Identification of the human skeletal stem cell. Cell 175:43-56 e21

Clinicaltrials.gov (2019) Periosteum in clinical trials. Access date 16 Dec 2019. https://clinicaltrials. gov $/$ ct $2 /$ results? cond $=$ periosteum $\&$ term $=\&$ cntry $=\&$ state $=\&$ city $=\&$ dist $=$

Colnot C (2009) Skeletal cell fate decisions within periosteum and bone marrow during bone regeneration. J Bone Miner Res Off J Am Soc Bone Miner Res 24:274-282

Cooper GM, Mooney MP, Gosain AK, Campbell PG, Losee JE, Huard J (2010) Testing the critical size in calvarial bone defects: revisiting the concept of a critical-size defect. Plast Reconstr Surg $125: 1685-1692$

Croitoru-Lamoury J, Lamoury FM, Caristo M, Suzuki K, Walker D, Takikawa O, Taylor R, Brew BJ (2011) Interferon-gamma regulates the proliferation and differentiation of mesenchymal stem cells via activation of indoleamine 2,3 dioxygenase (IDO). PLoS One 6:e14698

Davies DV (1963) The anatomy and physiology of joints. Physiotherapy 49:3-7

Debnath S, Yallowitz AR, McCormick J, Lalani S, Zhang T, Xu R, Li N, Liu Y, Yang YS, Eiseman $\mathrm{M}$ et al (2018) Discovery of a periosteal stem cell mediating intramembranous bone formation. Nature 562:133-139

Diaz-Flores L, Gutierrez R, Lopez-Alonso A, Gonzalez R, Varela H (1992) Pericytes as a supplementary source of osteoblasts in periosteal osteogenesis. Clin Orthop Relat Res 275:280-286

Dorronsoro A, Ferrin I, Salcedo JM, Jakobsson E, Fernandez-Rueda J, Lang V, Sepulveda P, Fechter K, Pennington D, Trigueros C (2014) Human mesenchymal stromal cells modulate T-cell responses through TNF-alpha-mediated activation of NF-kappaB. Eur J Immunol 44:480-488

Doucet C, Ernou I, Zhang Y, Llense JR, Begot L, Holy X, Lataillade JJ (2005) Platelet lysates promote mesenchymal stem cell expansion: a safety substitute for animal serum in cell-based therapy applications. J Cell Physiol 205:228-236

Duchamp de Lageneste O, Julien A, Abou-Khalil R, Frangi G, Carvalho C, Cagnard N, Cordier C, Conway SJ, Colnot C (2018) Periosteum contains skeletal stem cells with high bone regenerative potential controlled by Periostin. Nat Commun 9:773

Dwek JR (2010) The periosteum: what is it, where is it, and what mimics it in its absence? Skelet Radiol 39:319-323

Einhorn TA (1998) The cell and molecular biology of fracture healing. Clin Orthop Relat Res (355 Suppl):S7-S21. https://doi.org/10.1097/00003086-199810001-00003

Eyckmans J, Roberts SJ, Schrooten J, Luyten FP (2010) A clinically relevant model of osteoinduction: a process requiring calcium phosphate and BMP/Wnt signalling. J Cell Mol Med 14:1845-1856

Eyckmans J, Roberts SJ, Bolander J, Schrooten J, Chen CS, Luyten FP (2013) Mapping calcium phosphate activated gene networks as a strategy for targeted osteoinduction of human progenitors. Biomaterials 34:4612-4621

Fazzina R, Iudicone P, Fioravanti D, Bonanno G, Totta P, Zizzari IG, Pierelli L (2016) Potency testing of mesenchymal stromal cell growth expanded in human platelet lysate from different human tissues. Stem Cell Res Ther 7:122 
Fitzsimmons JS, Sanyal A, Gonzalez C, Fukumoto T, Clemens VR, O'Driscoll SW, Reinholz GG (2004) Serum-free media for periosteal chondrogenesis in vitro. J Orthop Res 22:716-725

Gupta P, Hall GN, Geris L, Luyten FP, Papantoniou I (2019) Human platelet lysate improves bone forming potential of human progenitor cells expanded in microcarrier-based dynamic culture. Stem Cells Transl Med 8:810-821

Hayashi O, Katsube Y, Hirose M, Ohgushi H, Ito H (2008) Comparison of osteogenic ability of rat mesenchymal stem cells from bone marrow, periosteum, and adipose tissue. Calcif Tissue Int 82:238-247

He A, Liu L, Luo X, Liu Y, Liu Y, Liu F, Wang X, Zhang Z, Zhang W, Liu W et al (2017a) Repair of osteochondral defects with in vitro engineered cartilage based on autologous bone marrow stromal cells in a swine model. Sci Rep 7:40489

He X, Bougioukli S, Ortega B, Arevalo E, Lieberman JR, McMahon AP (2017b) Sox9 positive periosteal cells in fracture repair of the adult mammalian long bone. Bone 103:12-19

Heathman TR, Nienow AW, McCall MJ, Coopman K, Kara B, Hewitt CJ (2015) The translation of cell-based therapies: clinical landscape and manufacturing challenges. Regen Med 10:49-64

Horner EA, Kirkham J, Wood D, Curran S, Smith M, Thomson B, Yang XB (2010) Long bone defect models for tissue engineering applications: criteria for choice. Tissue Eng Part B Rev $16: 263-271$

Ho-Shui-Ling A, Bolander J, Rustom LE, Johnson AW, Luyten FP, Picart C (2018) Bone regeneration strategies: engineered scaffolds, bioactive molecules and stem cells current stage and future perspectives. Biomaterials 180:143-162

Ingber DE, Mow VC, Butler D, Niklason L, Huard J, Mao J, Yannas I, Kaplan D, VunjakNovakovic G (2006) Tissue engineering and developmental biology: going biomimetic. Tissue Eng 12:3265-3283

International Stem Cell Initiative C, Akopian V, Andrews PW, Beil S, Benvenisty N, Brehm J, Christie M, Ford A, Fox V, Gokhale PJ et al (2010) Comparison of defined culture systems for feeder cell free propagation of human embryonic stem cells. In Vitro Cell Dev Biol Anim 46:247-258

Ionescu A, Kozhemyakina E, Nicolae C, Kaestner KH, Olsen BR, Lassar AB (2012) FoxA family members are crucial regulators of the hypertrophic chondrocyte differentiation program. Dev Cell 22:927-939

Isern J, Garcia-Garcia A, Martin AM, Arranz L, Martin-Perez D, Torroja C, Sanchez-Cabo F, Mendez-Ferrer S (2014) The neural crest is a source of mesenchymal stem cells with specialized hematopoietic stem cell niche function. elife 3:e03696

Ishikawa M, Ito H, Kitaori T, Murata K, Shibuya H, Furu M, Yoshitomi H, Fujii T, Yamamoto K, Matsuda S (2014) MCP/CCR2 signaling is essential for recruitment of mesenchymal progenitor cells during the early phase of fracture healing. PLoS One 9:e104954

Ito Y, Ochi M, Adachi N, Sugawara K, Yanada S, Ikada Y, Ronakorn P (2005) Repair of osteochondral defect with tissue-engineered chondral plug in a rabbit model. Arthroscopy 21:1155-1163

Ji W, Wang H, van den Beucken JJ, Yang F, Walboomers XF, Leeuwenburgh S, Jansen JA (2012) Local delivery of small and large biomolecules in craniomaxillofacial bone. Adv Drug Deliv Rev 64:1152-1164

Jonsdottir-Buch SM, Lieder R, Sigurjonsson OE (2013) Platelet lysates produced from expired platelet concentrates support growth and osteogenic differentiation of mesenchymal stem cells. PLoS One 8:e68984

Jung S, Panchalingam KM, Rosenberg L, Behie LA (2012) Ex vivo expansion of human mesenchymal stem cells in defined serum-free media. Stem Cells Int 2012:123030

Kitaori T, Ito H, Schwarz EM, Tsutsumi R, Yoshitomi H, Oishi S, Nakano M, Fujii N, Nagasawa T, Nakamura T (2009) Stromal cell-derived factor 1/CXCR4 signaling is critical for the recruitment of mesenchymal stem cells to the fracture site during skeletal repair in a mouse model. Arthritis Rheum 60:813-823 
Knothe Tate ML, Chang H, Moore SR, Knothe UR (2011) Surgical membranes as directional delivery devices to generate tissue: testing in an ovine critical sized defect model. PLoS One 6: e28702

Kong YY, Feige U, Sarosi I, Bolon B, Tafuri A, Morony S, Capparelli C, Li J, Elliott R, McCabe S et al (1999) Activated T cells regulate bone loss and joint destruction in adjuvant arthritis through osteoprotegerin ligand. Nature 402:304-309

Kudva AK, Luyten FP, Patterson J (2018) RGD-functionalized polyethylene glycol hydrogels support proliferation and in vitro chondrogenesis of human periosteum-derived cells. J Biomed Mater Res A 106:33-42

Kudva AK, Dikina AD, Luyten FP, Alsberg E, Patterson J (2019) Gelatin microspheres releasing transforming growth factor drive in vitro chondrogenesis of human periosteum derived cells in micromass culture. Acta Biomater 90:287-299

Kunisaki Y, Bruns I, Scheiermann C, Ahmed J, Pinho S, Zhang D, Mizoguchi T, Wei Q, Lucas D, Ito $\mathrm{K}$ et al (2013) Arteriolar niches maintain haematopoietic stem cell quiescence. Nature 502:637-643

Lambrechts T, Papantoniou I, Rice B, Schrooten J, Luyten FP, Aerts JM (2016) Large-scale progenitor cell expansion for multiple donors in a monitored hollow fibre bioreactor. Cytotherapy 18:1219-1233

Lammens J, Bauduin G, Driesen R, Moens P, Stuyck J, De Smet L, Fabry G (1998) Treatment of nonunion of the humerus using the Ilizarov external fixator. Clin Orthop Relat Res 353:223-230

Lammens J, Marechal M, Geris L, Van der Aa J, Van Hauwermeiren H, Luyten FP, Delport H (2017) Warning about the use of critical-size defects for the translational study of bone repair: analysis of a sheep Tibial model. Tissue Eng Part C Methods 23:694-699

Langer R, Vacanti JP (1993) Tissue engineering. Science 260:920-926

Lehmann W, Edgar CM, Wang K, Cho TJ, Barnes GL, Kakar S, Graves DT, Rueger JM, Gerstenfeld LC, Einhorn TA (2005) Tumor necrosis factor alpha (TNF-alpha) coordinately regulates the expression of specific matrix metalloproteinases (MMPS) and angiogenic factors during fracture healing. Bone 36:300-310

Lenas P, Moos M, Luyten FP (2009a) Developmental engineering: a new paradigm for the design and manufacturing of cell-based products. Part I: from three-dimensional cell growth to biomimetics of in vivo development. Tissue Eng Part B Rev 15:381-394

Lenas P, Moos M, Luyten FP (2009b) Developmental engineering: a new paradigm for the design and manufacturing of cell-based products. Part II: from genes to networks: tissue engineering from the viewpoint of systems biology and network science. Tissue Eng Part B Rev 15:395-422

Li W, Kohara H, Uchida Y, James JM, Soneji K, Cronshaw DG, Zou YR, Nagasawa T, Mukouyama YS (2013) Peripheral nerve-derived CXCL12 and VEGF-A regulate the patterning of arterial vessel branching in developing limb skin. Dev Cell 24:359-371

Li Z, Meyers CA, Chang L, Lee S, Li Z, Tomlinson R, Hoke A, Clemens TL, James AW (2019) Fracture repair requires TrkA signaling by skeletal sensory nerves. J Clin Invest 129:5137-5150

Luyten FP, Roberts SJ (2018) Close to the bone - in search of the skeletal stem cell. Nat Rev Rheumatol 14:687-688

Ma J, Both SK, Yang F, Cui FZ, Pan J, Meijer GJ, Jansen JA, van den Beucken JJ (2014) Concise review: cell-based strategies in bone tissue engineering and regenerative medicine. Stem Cells Transl Med 3:98-107

Maes C, Kobayashi T, Selig MK, Torrekens S, Roth SI, Mackem S, Carmeliet G, Kronenberg HM (2010) Osteoblast precursors, but not mature osteoblasts, move into developing and fractured bones along with invading blood vessels. Dev Cell 19:329-344

Manabe N, Kawaguchi H, Chikuda H, Miyaura C, Inada M, Nagai R, Nabeshima Y, Nakamura K, Sinclair AM, Scheuermann RH et al (2001) Connection between B lymphocyte and osteoclast differentiation pathways. J Immunol 167:2625-2631

Mapara M, Thomas BS, Bhat KM (2012) Rabbit as an animal model for experimental research. Dent Res J 9:111-118 
Marecic O, Tevlin R, McArdle A, Seo EY, Wearda T, Duldulao C, Walmsley GG, Nguyen A, Weissman IL, Chan CK et al (2015) Identification and characterization of an injury-induced skeletal progenitor. Proc Natl Acad Sci U S A 112:9920-9925

Masquelet AC, Begue T (2010) The concept of induced membrane for reconstruction of long bone defects. Orthop Clin North Am 41:27-37; table of contents

Matthyssen S, Ni Dhubhghaill S, Van Gerwen V, Zakaria N (2017) Xeno-free cultivation of mesenchymal stem cells from the corneal Stroma. Invest Ophthalmol Vis Sci 58:2659-2665

McKibbin B (1978) The biology of fracture healing in long bones. J Bone Joint Surg (Br) 60B:150-162

Mendes LF, Katagiri H, Tam WL, Chai YC, Geris L, Roberts SJ, Luyten FP (2018) Advancing osteochondral tissue engineering: bone morphogenetic protein, transforming growth factor, and fibroblast growth factor signaling drive ordered differentiation of periosteal cells resulting in stable cartilage and bone formation in vivo. Stem Cell Res Ther 9:42

Mendez-Ferrer S, Michurina TV, Ferraro F, Mazloom AR, Macarthur BD, Lira SA, Scadden DT, Ma'ayan A, Enikolopov GN, Frenette PS (2010) Mesenchymal and haematopoietic stem cells form a unique bone marrow niche. Nature 466:829-834

Mendez-Ferrer S, Scadden DT, Sanchez-Aguilera A (2015) Bone marrow stem cells: current and emerging concepts. Ann N Y Acad Sci 1335:32-44

Mizuhashi K, Ono W, Matsushita Y, Sakagami N, Takahashi A, Saunders TL, Nagasawa T, Kronenberg HM, Ono N (2018) Resting zone of the growth plate houses a unique class of skeletal stem cells. Nature 563:254-258

Mizuno K, Mineo K, Tachibana T, Sumi M, Matsubara T, Hirohata K (1990) The osteogenetic potential of fracture haematoma. Subperiosteal and intramuscular transplantation of the haematoma. J Bone Joint Surg (Br) 72:822-829

Moore SR, Milz S, Knothe Tate ML (2014) Periosteal thickness and cellularity in mid-diaphyseal cross-sections from human femora and tibiae of aged donors. J Anat 224:142-149

Moreira CA, Dempster DW, Baron R (2000) Anatomy and ultrastructure of bone - Histogenesis, growth and remodeling. In: Feingold KR, Anawalt B, Boyce A, Chrousos G, Dungan K, Grossman A, Hershman JM, Kaltsas G, Koch C, Kopp P et al (eds) Endotext [Internet]. South Dartmouth (MA)

Morikawa S, Mabuchi Y, Kubota Y, Nagai Y, Niibe K, Hiratsu E, Suzuki S, Miyauchi-Hara C, Nagoshi N, Sunabori T et al (2009) Prospective identification, isolation, and systemic transplantation of multipotent mesenchymal stem cells in murine bone marrow. J Exp Med 206:2483-2496

Newton PT, Li L, Zhou B, Schweingruber C, Hovorakova M, Xie M, Sun X, Sandhow L, Artemov AV, Ivashkin E et al (2019) A radical switch in clonality reveals a stem cell niche in the epiphyseal growth plate. Nature 567:234-238

Nilsson Hall G, Mendes LF, Gklava C, Geris L, Luyten FP, Papantoniou I (2020) Developmentally engineered callus organoid bioassemblies exhibit predictive in vivo Long bone healing. Adv Sci n/a:1902295

Ono N, Ono W, Mizoguchi T, Nagasawa T, Frenette PS, Kronenberg HM (2014) Vasculatureassociated cells expressing nestin in developing bones encompass early cells in the osteoblast and endothelial lineage. Dev Cell 29:330-339

Ortinau LC, Wang H, Lei K, Deveza L, Jeong Y, Hara Y, Grafe I, Rosenfeld SB, Lee D, Lee B et al (2019) Identification of functionally distinct Mx1+alphaSMA+ periosteal skeletal stem cells. Cell Stem Cell 25:784-796 e785

Owen M, Friedenstein AJ (1988) Stromal stem cells: marrow-derived osteogenic precursors. CIBA Found Symp 136:42-60

Pineault KM, Song JY, Kozloff KM, Lucas D, Wellik DM (2019) Hox11 expressing regional skeletal stem cells are progenitors for osteoblasts, chondrocytes and adipocytes throughout life. Nat Commun 10:3168

Pobloth AM, Duda GN, Giesecke MT, Dienelt A, Schwabe P (2015) High-dose recombinant human bone morphogenetic protein-2 impacts histological and biomechanical properties of a cervical spine fusion segment: results from a sheep model. J Tissue Eng Regen Med 11(5):1514-1523 
Reinisch A, Bartmann C, Rohde E, Schallmoser K, Bjelic-Radisic V, Lanzer G, Linkesch W, Strunk D (2007) Humanized system to propagate cord blood-derived multipotent mesenchymal stromal cells for clinical application. Regen Med 2:371-382

Rhinelander FW, Baragry R (1962) Microangiography in bone healing. I. Undisplaced closed fractures. J Bone Joint Surg Am 44-A:1273-1298

Roberts SJ, Geris L, Kerckhofs G, Desmet E, Schrooten J, Luyten FP (2011) The combined bone forming capacity of human periosteal derived cells and calcium phosphates. Biomaterials 32:4393-4405

Robey P (2017) "Mesenchymal stem cells": fact or fiction, and implications in their therapeutic use. F1000Res 6:F1000 Faculty Rev-524

Ryan JM (1979) Effect of different fetal bovine serum concentrations on the replicative life span of cultured chick cells. In Vitro 15:895-899

Sacchetti B, Funari A, Michienzi S, Di Cesare S, Piersanti S, Saggio I, Tagliafico E, Ferrari S, Robey PG, Riminucci M et al (2007) Self-renewing osteoprogenitors in bone marrow sinusoids can organize a hematopoietic microenvironment. Cell 131:324-336

Sadtler K, Wolf MT, Ganguly S, Moad CA, Chung L, Majumdar S, Housseau F, Pardoll DM, Elisseeff JH (2019) Divergent immune responses to synthetic and biological scaffolds. Biomaterials 192:405-415

Salazar VS, Gamer LW, Rosen V (2016) BMP signalling in skeletal development, disease and repair. Nat Rev Endocrinol 12:203-221

Salazar VS, Capelo LP, Cantu C, Zimmerli D, Gosalia N, Pregizer S, Cox K, Ohte S, Feigenson M, Gamer L et al (2019) Reactivation of a developmental Bmp2 signaling center is required for therapeutic control of the murine periosteal niche. elife 8:e42386

Salvade A, Della Mina P, Gaddi D, Gatto F, Villa A, Bigoni M, Perseghin P, Serafini M, Zatti G, Biondi A et al (2010) Characterization of platelet lysate cultured mesenchymal stromal cells and their potential use in tissue-engineered osteogenic devices for the treatment of bone defects. Tissue Eng Part C Methods 16:201-214

Schell H, Duda GN, Peters A, Tsitsilonis S, Johnson KA, Schmidt-Bleek K (2017) The haematoma and its role in bone healing. J Exp Orthop 4:5

Schinhan M, Gruber M, Vavken P, Dorotka R, Samouh L, Chiari C, Gruebl-Barabas R, Nehrer S (2012) Critical-size defect induces unicompartmental osteoarthritis in a stable ovine knee. J Orthop Res 30:214-220

Segal AW (2005) How neutrophils kill microbes. Annu Rev Immunol 23:197-223

Shahdadfar A, Fronsdal K, Haug T, Reinholt FP, Brinchmann JE (2005) In vitro expansion of human mesenchymal stem cells: choice of serum is a determinant of cell proliferation, differentiation, gene expression, and transcriptome stability. Stem Cells 23:1357-1366

Shi Y, He G, Lee WC, McKenzie JA, Silva MJ, Long F (2017) Gli1 identifies osteogenic progenitors for bone formation and fracture repair. Nat Commun 8:2043

Shields LB, Raque GH, Glassman SD, Campbell M, Vitaz T, Harpring J, Shields CB (2006) Adverse effects associated with high-dose recombinant human bone morphogenetic protein-2 use in anterior cervical spine fusion. Spine 31:542-547

Song MK, Lee ZH, Kim HH (2015) Adseverin mediates RANKL-induced osteoclastogenesis by regulating NFATc1. Exp Mol Med 47:e199

Stockmann P, Park J, von Wilmowsky C, Nkenke E, Felszeghy E, Dehner JF, Schmitt C, Tudor C, Schlegel KA (2012) Guided bone regeneration in pig calvarial bone defects using autologous mesenchymal stem/progenitor cells - a comparison of different tissue sources. J Craniomaxillofac Surg 40:310-320

Struillou X, Boutigny H, Soueidan A, Layrolle P (2010) Experimental animal models in periodontology: a review. Open Dent J 4:37-47

Strunk D, Lozano M, Marks DC, Loh YS, Gstraunthaler G, Schennach H, Rohde E, LanerPlamberger S, Oller M, Nystedt J et al (2018) International forum on GMP-grade human platelet lysate for cell propagation: summary. Vox Sang 113:80-87

Stuart RC, Hehir D (1992) Comparative efficacy of cimetidine, famotidine, ranitidine, and mylanta in postoperative stress ulcers. Gastroenterology 102:1091 
Szpalski C, Barr J, Wetterau M, Saadeh PB, Warren SM (2010) Cranial bone defects: current and future strategies. Neurosurg Focus 29:E8

Tavassoli M, Crosby WH (1968) Transplantation of marrow to extramedullary sites. Science 161:54-56

Tsuji K, Bandyopadhyay A, Harfe BD, Cox K, Kakar S, Gerstenfeld L, Einhorn T, Tabin CJ, Rosen $\mathrm{V}$ (2006) BMP2 activity, although dispensable for bone formation, is required for the initiation of fracture healing. Nat Genet 38:1424-1429

van Gastel N, Torrekens S, Roberts SJ, Moermans K, Schrooten J, Carmeliet P, Luttun A, Luyten FP, Carmeliet G (2012) Engineering vascularized bone: osteogenic and proangiogenic potential of murine periosteal cells. Stem Cells 30:2460-2471

van Griensven M (2015) Preclinical testing of drug delivery systems to bone. Adv Drug Deliv Rev

Vashishth D (2008) Small animal bone biomechanics. Bone 43:794-797

Verbeeck L, Geris L, Tylzanowski P, Luyten FP (2019) Uncoupling of in-vitro identity of embryonic limb derived skeletal progenitors and their in-vivo bone forming potential. Sci Rep 9:5782

Via AG, Frizziero A, Oliva F (2012) Biological properties of mesenchymal stem cells from different sources. Muscle Ligaments Tendons J 2:154-162

Wakitani S, Imoto K, Yamamoto T, Saito M, Murata N, Yoneda M (2002) Human autologous culture expanded bone marrow mesenchymal cell transplantation for repair of cartilage defects in osteoarthritic knees. Osteoarthr Cartil 10:199-206

Wang X, Mabrey JD, Agrawal CM (1998) An interspecies comparison of bone fracture properties. Biomed Mater Eng 8:1-9

Wehrhan F, Amann K, Molenberg A, Lutz R, Neukam FW, Schlegel KA (2013) Critical size defect regeneration using PEG-mediated BMP-2 gene delivery and the use of cell occlusive barrier membranes - the osteopromotive principle revisited. Clin Oral Implants Res 24:910-920

Worthley DL, Churchill M, Compton JT, Tailor Y, Rao M, Si Y, Levin D, Schwartz MG, Uygur A, Hayakawa $\mathrm{Y}$ et al (2015) Gremlin 1 identifies a skeletal stem cell with bone, cartilage, and reticular stromal potential. Cell 160:269-284

Xian CJ, Zhou FH, McCarty RC, Foster BK (2004) Intramembranous ossification mechanism for bone bridge formation at the growth plate cartilage injury site. J Orthop Res 22:417-426

Xu S, Lin K, Wang Z, Chang J, Wang L, Lu J, Ning C (2008) Reconstruction of calvarial defect of rabbits using porous calcium silicate bioactive ceramics. Biomaterials 29:2588-2596

Yamashita A, Morioka M, Kishi H, Kimura T, Yahara Y, Okada M, Fujita K, Sawai H, Ikegawa S, Tsumaki N (2014) Statin treatment rescues FGFR3 skeletal dysplasia phenotypes. Nature 513:507-511

Yamashita A, Morioka M, Yahara Y, Okada M, Kobayashi T, Kuriyama S, Matsuda S, Tsumaki N (2015) Generation of scaffoldless hyaline cartilaginous tissue from human iPSCs. Stem Cell Rep 4:404-418

Ye L, Mishina Y, Chen D, Huang H, Dallas SL, Dallas MR, Sivakumar P, Kunieda T, Tsutsui TW, Boskey A et al (2005) Dmp1-deficient mice display severe defects in cartilage formation responsible for a chondrodysplasia-like phenotype. J Biol Chem 280:6197-6203

Yoshimura H, Muneta T, Nimura A, Yokoyama A, Koga H, Sekiya I (2007) Comparison of rat mesenchymal stem cells derived from bone marrow, synovium, periosteum, adipose tissue, and muscle. Cell Tissue Res 327:449-462

Yu N, Plachokova A, Yang F, Walboomers X, Jansen J (2013) Engineering of dental tissues: scaffolds and preclinical models. In: Stem cells in craniofacial development, regeneration and repair. Wiley-Blackwell Press

Zhou BO, Yue R, Murphy MM, Peyer JG, Morrison SJ (2014) Leptin-receptor-expressing mesenchymal stromal cells represent the main source of bone formed by adult bone marrow. Cell Stem Cell 15:154-168 